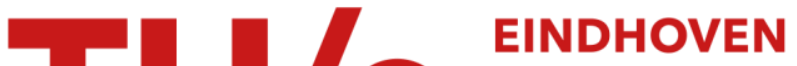 UNIVERSITY OF TECHNOLOGY
}

\section{Effective streamer discharge control by tailored nanosecond- pulsed high-voltage waveforms}

Citation for published version (APA):

Huiskamp, T., Ton, C., Azizi, M., van Oorschot, J. J., \& Höft, H. (2021). Effective streamer discharge control by tailored nanosecond-pulsed high-voltage waveforms. Journal of Physics D: Applied Physics, 55(2), [024001]. https://doi.org/10.1088/1361-6463/ac2969

DOI:

10.1088/1361-6463/ac2969

Document status and date:

Published: 08/10/2021

Document Version:

Publisher's PDF, also known as Version of Record (includes final page, issue and volume numbers)

Please check the document version of this publication:

- A submitted manuscript is the version of the article upon submission and before peer-review. There can be important differences between the submitted version and the official published version of record. People interested in the research are advised to contact the author for the final version of the publication, or visit the $\mathrm{DOI}$ to the publisher's website.

- The final author version and the galley proof are versions of the publication after peer review.

- The final published version features the final layout of the paper including the volume, issue and page numbers.

Link to publication

\section{General rights}

Copyright and moral rights for the publications made accessible in the public portal are retained by the authors and/or other copyright owners and it is a condition of accessing publications that users recognise and abide by the legal requirements associated with these rights.

- Users may download and print one copy of any publication from the public portal for the purpose of private study or research.

- You may not further distribute the material or use it for any profit-making activity or commercial gain

- You may freely distribute the URL identifying the publication in the public portal.

If the publication is distributed under the terms of Article 25fa of the Dutch Copyright Act, indicated by the "Taverne" license above, please follow below link for the End User Agreement:

www.tue.nl/taverne

Take down policy

If you believe that this document breaches copyright please contact us at:

openaccess@tue.nl

providing details and we will investigate your claim. 
PAPER • OPEN ACCESS

\section{Effective streamer discharge control by tailored nanosecond-pulsed high-voltage waveforms}

To cite this article: T Huiskamp et al 2022 J. Phys. D: Appl. Phys. 55024001

View the article online for updates and enhancements.
You may also like

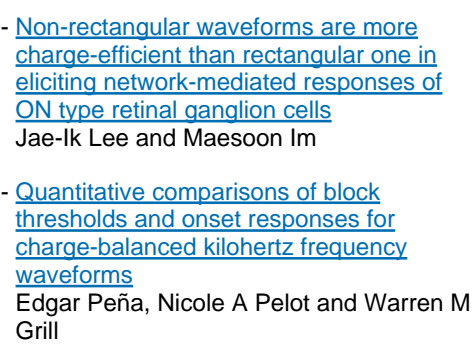

A $6 \mathrm{kV}$ arbitrary waveform generator for the Tevatron Electron Lens $\mathrm{H}$ Pfeffer and G Saewert

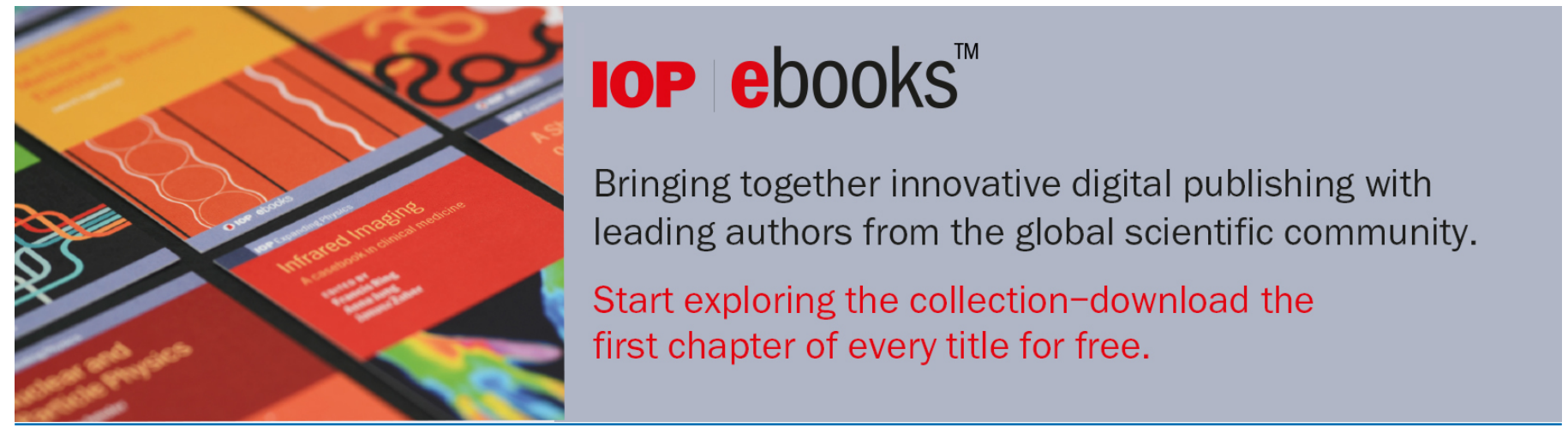




\title{
Effective streamer discharge control by tailored nanosecond-pulsed high-voltage waveforms
}

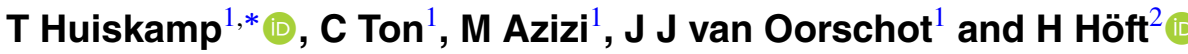 \\ ${ }^{1}$ Department of Electrical Engineering, Electrical Energy Systems group, Eindhoven University of \\ Technology, PO Box 513, 5600 MB Eindhoven, The Netherlands \\ ${ }^{2}$ Leibniz Institute for Plasma Science and Technology (INP Greifswald), Felix-Hausdorff-Str. 2, 17489 \\ Greifswald, Germany \\ E-mail: t.huiskamp@tue.nl
}

Received 31 May 2021, revised 13 August 2021

Accepted for publication 23 September 2021

Published 8 October 2021

\begin{abstract}
In this paper we present our solid-state nanosecond pulse source (the solid-state impedance-matched Marx generator) which can generate arbitrary waveforms and which can be used for pulsed discharge generation. The purpose of the development of such a generator is twofold: by being able to change the waveform at will, we aim to control the discharge generated by such pulses very precisely which can be very useful for plasma applications, but also for more fundamental studies. In the presented study, we applied the arbitrary-waveform pulse source for streamer discharge generation in a cylinder-wire-like arrangement and used the arbitrary-waveform capability to change the rise time (in our experiments we used 6.8-26.2 ns) of unipolar positive pulses with $6-10 \mathrm{kV}$ amplitude and $80 \mathrm{~ns}$ duration. Additionally, we introduced variations of a step in the rising edge of the waveform. We performed measurements both in air and nitrogen to electrically characterize the discharge while analyzing the streamer propagation in the plasma reactor with intensified charge-coupled device imaging and measured ozone generation (in air). The results show that we can indeed control the propagation of the streamer discharge with the stepped waveform, but that the rise-time variation has little effect on the streamer propagation in our system. However, the streamer velocity and structure differs significantly comparing discharges in nitrogen and air for the same applied voltage waveform. Additionally, for some of the stepped waveforms we found a slight increase of the ozone yield for air at low overall energy densities.
\end{abstract}

Keywords: pulsed power, streamer discharge, transient plasma, nanosecond high-voltage pulses (Some figures may appear in colour only in the online journal)

\footnotetext{
* Author to whom any correspondence should be addressed.
} 


\section{Introduction}

Non-thermal plasmas are efficient in producing highly reactive radical species and energetic photons $[1,2]$ and have been used for industrial and environmental applications for more than 100 years $[1,3]$. These transient plasmas can be effectively used for water decontamination, air purification, surface modification, sterilization and other applications $[1,4,5]$.

In general, transient-plasma research for environmental purposes focuses on two areas: decontamination (e.g. air purification, water purification, etc.) [6-9] and plasma-activated water (PAW) generation [10-13]. For air purification, research has shown that transient plasmas generated by short nanosecond high-voltage pulses are very efficient [14-22]. More specifically, researchers have noted that the pulse duration and the rise time of the applied high-voltage pulse have a significant influence on the radical yield of the transient plasmas generated with these pulses; shorter pulses result in higher yields [14-17, 21]. For instance, for shorter rising pulses, streamers produce a higher reduced electric field at their head, resulting in a higher oxygen radical yield [23]. Therefore, using fast-rising pulses is often important. However, to study the effect of different pulse parameters on discharge properties for air purification applications and fundamental studies, we would ideally have a pulse source that can produce arbitrary waveforms, while maintaining the possibility of using very fast rising pulses. Furthermore, it is known that the shape of rising slope of the applied high-voltage pulse has direct consequences on the streamer breakdown, as shown e.g. for air [24] and for pure nitrogen [25] at atmospheric pressure.

The discharges used for PAW generation do not necessarily have to be operated by the fastest rising pulses and have to be adapted to the specific application (e.g. disinfection and/or fertilizer production). Different studies show that for instance hydrogen peroxide, nitrate and nitrite (all useful components in PAW) are generated in different concentrations in the water depending on the type of plasma and the way it is generated [26-30]. Therefore, for PAW generation it is of great benefit to not just have the shortest and fastest pulses available (for efficient reactive oxygen species generation), but to be able to generate also longer pulses (to heat up the discharge and generate more reactive nitrogen species). Ideally, pulsed plasma generation for PAW should be completely controllable through an arbitrary high-voltage waveform and therefore also for this application the need arises for a fast pulse source with the capability to generate arbitrary waveforms.

Another promising utilization of arbitrary high-voltage pulses is the investigation of pulsed-driven dielectric barrier discharges (DBD), since the breakdown and especially the pre-phase, which determines the streamer initiation, can be directly controlled by variable high-voltage slopes [31].

There are many types of high-voltage pulse sources available for plasma generation (for a full overview, see [32]). For extremely fast pulses we used a spark-gap based system (200 ps rise time, up to $50 \mathrm{kV}$ amplitude and $0.5-10$ ns duration) for high yields in air purification processes [14] and there are other examples in literature (e.g. [16, 17]). However, spark-gap based systems are commercially less attractive and typically not capable of arbitrary-waveform generation, which is why we turn to solid-state systems, which can also produce very fast pulses (e.g. the SOS pulse sources [33]) and high plasmaprocessing yields (e.g. [34]). Unfortunately, there were only three main types of solid-state pulse sources that can generate arbitrary waveform high-voltage pulses: the solid-state Marx generator (e.g. [35]), the solid-state linear transformer driver (LTD) (e.g. [36]) and the solid-state inductive adder (e.g. [37]). While such pulse sources can generate arbitrary waveforms, they typically have a relatively slow rise time (10-20 ns at best) and we need the fastest possible rise time (ideally less than several nanoseconds) for high-yield plasma processing. Therefore, we introduced a new solid-state pulse topology capable of both fast rise-time pulses and arbitrary waveforms: the solid-state impedance-matched Marx generator (IMG), which was described in detail in [38] and of which a brief concept and a description of its capabilities will be given in section 2. In this paper, we will show the first results of pulsed streamer discharge generation with the arbitrary waveforms from a solidstate IMG.

Besides being useful for air-purification studies and PAW generation, the reason for the development of the solid-state IMG is for fundamental discharge studies and to verify numerical streamer models. Such models are getting to a state where they can accurately predict streamer propagation and branching in 3D in all kinds environmental conditions (pressures, gases, etc) [2, 39-41]. These models are a valuable tool for developing plasma processes, as such tools can model quantities that can be difficult to measure experimentally. We can further improve the accuracy of these models by comparing them to experimental results [2]. Simply said: when numerical models can faithfully reproduce experimental results with the strangest high-voltage waveforms we can produce, we can be more and more sure of the accuracy of these models (and improve them further) [42].

The purpose of this paper is to present the principle of arbitrary waveform generation for streamer discharge control (section 2) and to present the first experiments where we show that we can indeed control the streamer discharge by changing the shape of the rising edge of the high-voltage waveform (sections 3 and 4). In order to visualize the effect of the waveform on discharge generation, we imaged the streamer development with ICCD (intensified charge-coupled device) imaging and measured ozone concentrations generated by the discharge and electrical energies consumed by the discharge to calculate the ozone production yield. A wire-to-cylinder arrangement was used for these experiments to have a bigger load compared to a pin-to-plate arrangement, which is closer to reactors in potential applications.

\section{Principle of arbitrary waveform solid-state nanosecond pulsed power technology and the solid-state IMG}

To generate arbitrary waveforms with pulsed high-voltage sources, such sources make use of a multi-stage topology, 


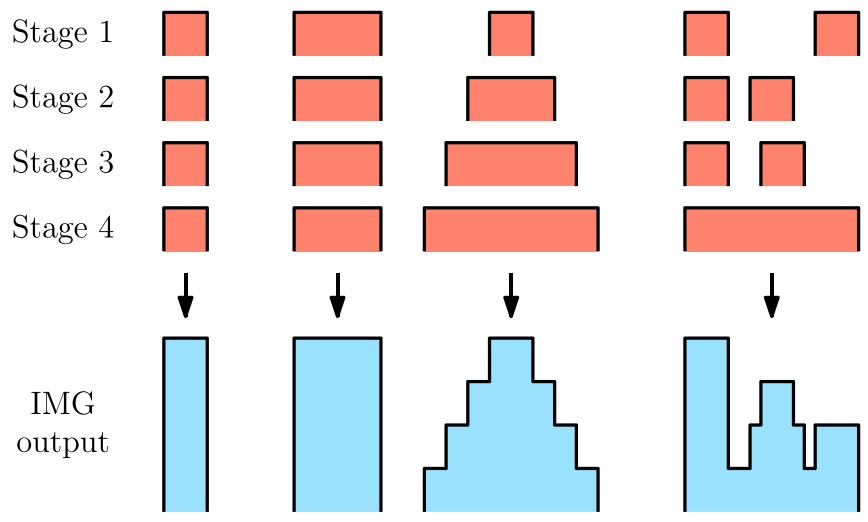

Figure 1. Four examples of how a 4-stage multi-stage pulse topology can achieve arbitrary waveform generation. Each stage adds its output voltage independently to the total output voltage of the IMG.

such as the Marx generator [43], the LTD [44] or the recently introduced IMG [45]. As mentioned in the introduction, of each of these topologies there are now solid-state versions $[35,36,38]$. The way in which such topologies can generate arbitrary waveforms is by independently triggering the stages and then the topology ensures that the output of these linearly add to the output waveform. Examples illustrating the working principle of the IMG are shown in figure 1 and also in $[46,47]$ for a solid-state LTD (and was even used to do some simple discharge control). In essence, such pulse sources consist of many smaller pulse sources which can be individually controlled and all contribute to the total output pulse.

The reason that we introduced the solid-state IMG and not use a solid-state LTD or regular solid-state Marx generator is the rise time. The IMG is capable of generating extremely fast pulses due to its impedance-matched design (for more details, see [38]) and is therefore ideally suited for efficient pulsed streamer discharge generation. The only downside to the IMG when considering arbitrary waveform generation is that if it is perfectly impedance-matched, using a scheme as in figure 1 will introduce pulse reflections that will (slightly) distort the waveform (because we violate the impedancematching criterion concerning triggering). However, for pulse rise times that are longer than the propagation time of the pulses through the IMG structure, this is not an issue and in the implementation presented in this paper that is also the case.

The concept of the IMG is sketched in figure 2. Many small pulse sources (FSSMs) are placed in parallel and in series to form the total pulse source. Every stage consists of several FSSM's placed in parallel (typically on a single circuit board) which connects to a central coaxial transmission line. The pulse from every stage then couples into the transmission line and the output of the transmission line is the output of the pulse source.

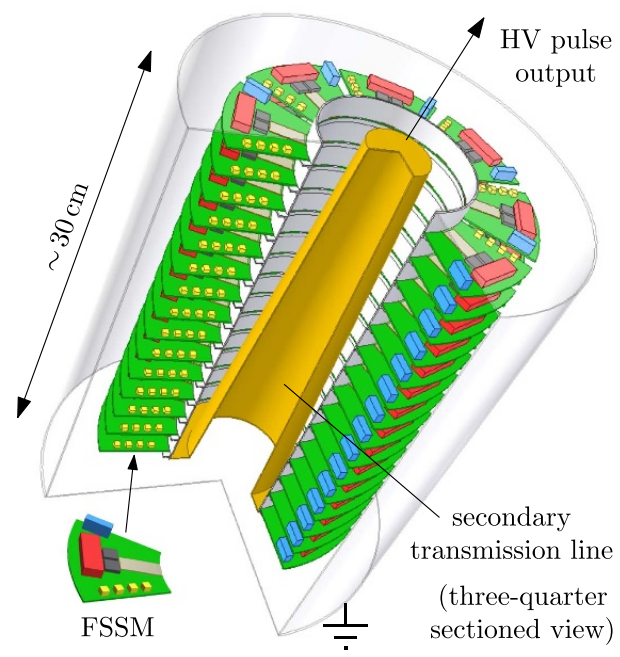

Figure 2. Sketch of the solid-state IMG concept. Multiple circular stages are connected in series and each stage is a parallel connection of fast semiconductor switch modules (FSSMs). Each FSSM produces a pulse which travels into the central coaxial structure. When perfectly impedance-matched, all pulses add up at the load, producing a high-voltage pulse (the number of stages, FSSMs per stage and layout of the FSSMs used in this sketch are just an example). (0 [2019] IEEE. Reprinted, with permission, from [38].

One of the solid-state IMG implementations we made is shown in figure 3. It is a 14-stage IMG capable of generating $14 \mathrm{kV}$ output pulses (each stage outputs up to $1 \mathrm{kV}$ ). By individually controlling the stages, arbitrary waveforms can be generated (like the example in figure 1). Figure 4 shows examples of the real output pulses of this IMG. Two "normal' rectangular pulses are shown, as well as two arbitrary waveforms. This specific solid-state IMG was developed for PAW generation. Another version of a solid-state IMG will be used in this paper. It is an 8-stage IMG capable of pulses of up to around $11 \mathrm{kV}$ (1.4 kV per stage) and is in all aspects similar to figure 3 . Because of the limitations that exist in the current solid-state IMGs the arbitrary-waveform variation in the experiments in this paper will focus on changing the rising edge of the high-voltage pulse, which is the time when the streamers propagate in our plasma reactor (which will be described in section 3).

Figure 5 shows the (arbitrary) waveforms we used for the experiments in this paper. The fastest rise time (10\%-90\%) when the plasma reactor that we used is connected is $6.8 \mathrm{~ns}$ and the pulse has a duration of around $80 \mathrm{~ns}$. By delaying some stages of the solid-state IMG we can obtain waveforms with a slower rise time (figure 5(a)). It has to be noted that using a 8 -stage IMG enables a (relative) precise rising slope variation even for nanosecond rise-times, especially compared to the high-voltage pulses used in [24, 25]. Figure 5(b) shows waveforms where $X$ stages have been delayed by $N$ nanoseconds. These waveforms are annotated as $X \mathrm{~S} . N \mathrm{D}$ and will be used in section 4 together with the waveforms with different rise times. 


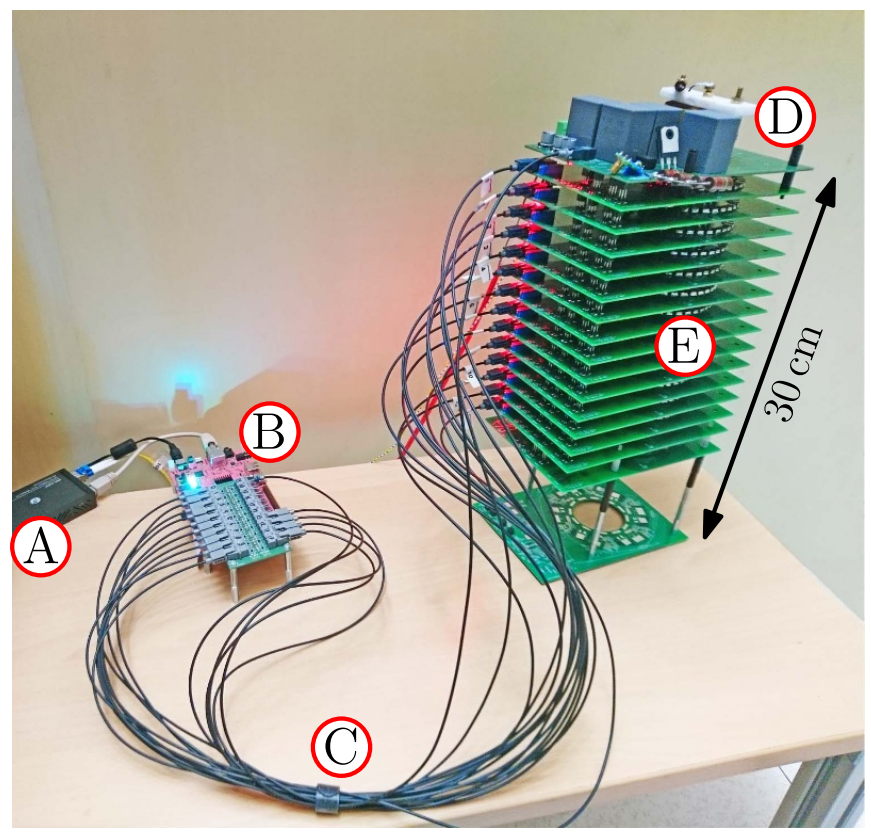

Figure 3. A 14-stage solid-state IMG as an example. It is capable of producing positive pulses up to around $14 \mathrm{kV}$ at an average power of over $1 \mathrm{~kW}$. (A) Optical ethernet connection. (B) FPGA (field-programmable gate array) control board. (C) Optical fibers to control the stages. (D) Charging PCB (printed circuit board) that controls the charging of the IMG stages. (E) The IMG stages. The central coaxial transmission line lies at the heart of the PCBs, but cannot be seen in this photo.

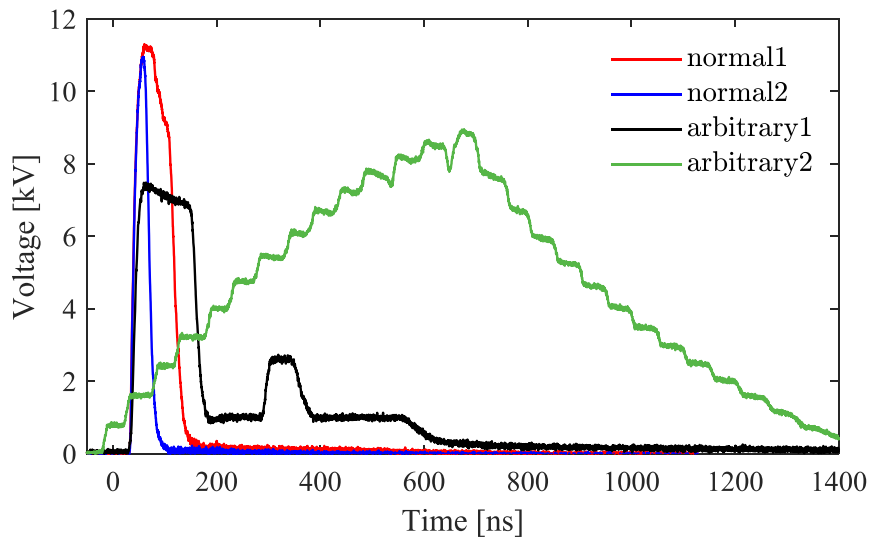

Figure 4. Some example waveforms from the IMG shown in figure 3 .

\section{Experimental setup}

Figure 6 shows the total experimental setup for the experiments in this paper. An EMC cabinet houses a laptop which controls the spectrometer and the IMG (through the FPGA control board), the oscilloscope, the spectrometer and UV light source. Each item will be discussed below.

\subsection{Pulse source}

The pulse source used for the experiments is the 8-stage solidstate IMG described in the previous section. It is connected to

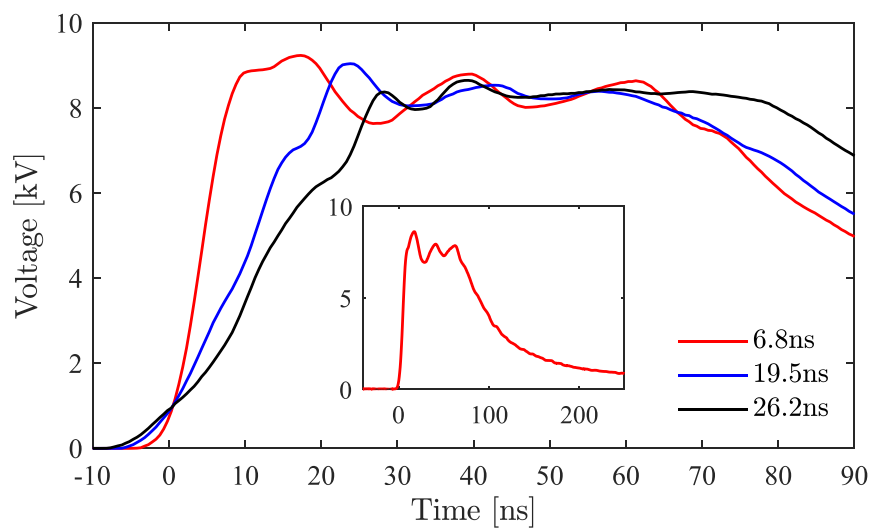

(a)

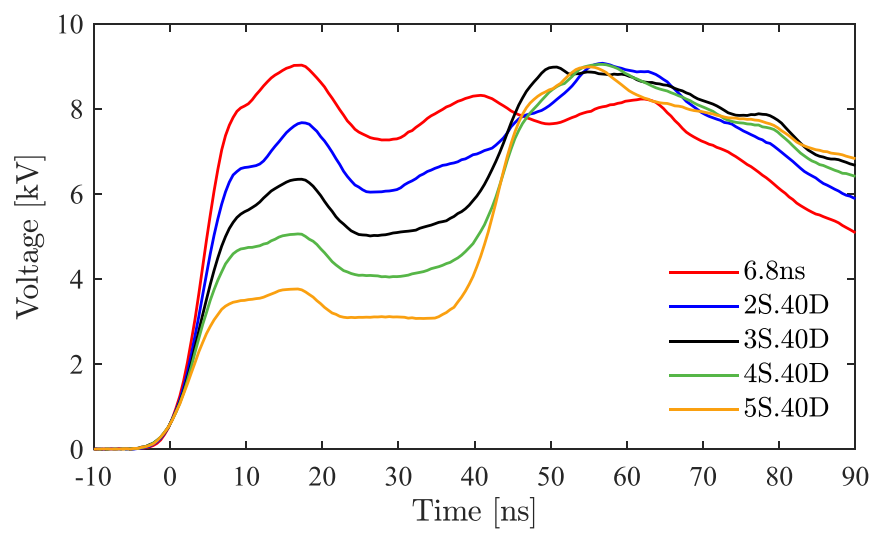

(b)

Figure 5. The different waveform from the 8-stage IMG that we used in the experiments of this paper. (a) The three pulses used for the rise-time-variation experiment. By delaying some stages of the IMG, we can obtain $6.8 \mathrm{~ns}, 19.5 \mathrm{~ns}$ and $26.2 \mathrm{~ns}$ rise-time pulses. Each pulse has a FWHM duration of around $(80 \pm 2) \mathrm{ns}$. The inset shows the entire $6.8 \mathrm{~ns}$ rise-time pulse. (b) These waveforms all have no, two, three, four or five stages delayed by $40 \mathrm{~ns}$ with respect to the $6.8 \mathrm{~ns}$ pulse (the delayed waveforms are denoted respectively 2S.40D, 3S.40D, etc).

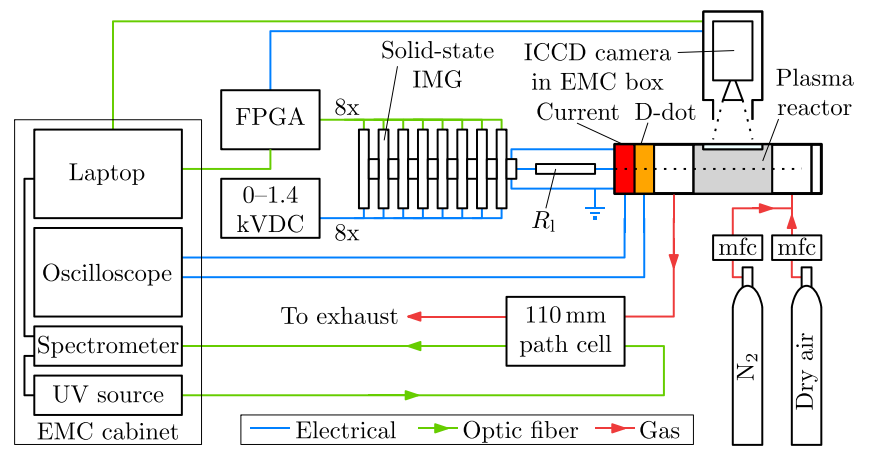

Figure 6. A schematic representation of the complete experimental setup.

a 0-20 kV DC PSU (Fug HCK 1600-20 000) that is used up to $1.4 \mathrm{kV}$ and to an FPGA board (via optic fibers) that controls the stages. The FPGA is connected by ethernet (optically isolated) to a laptop which programs the FPGA with the desired output waveform. The solid-state IMG is capable of generating pulses 


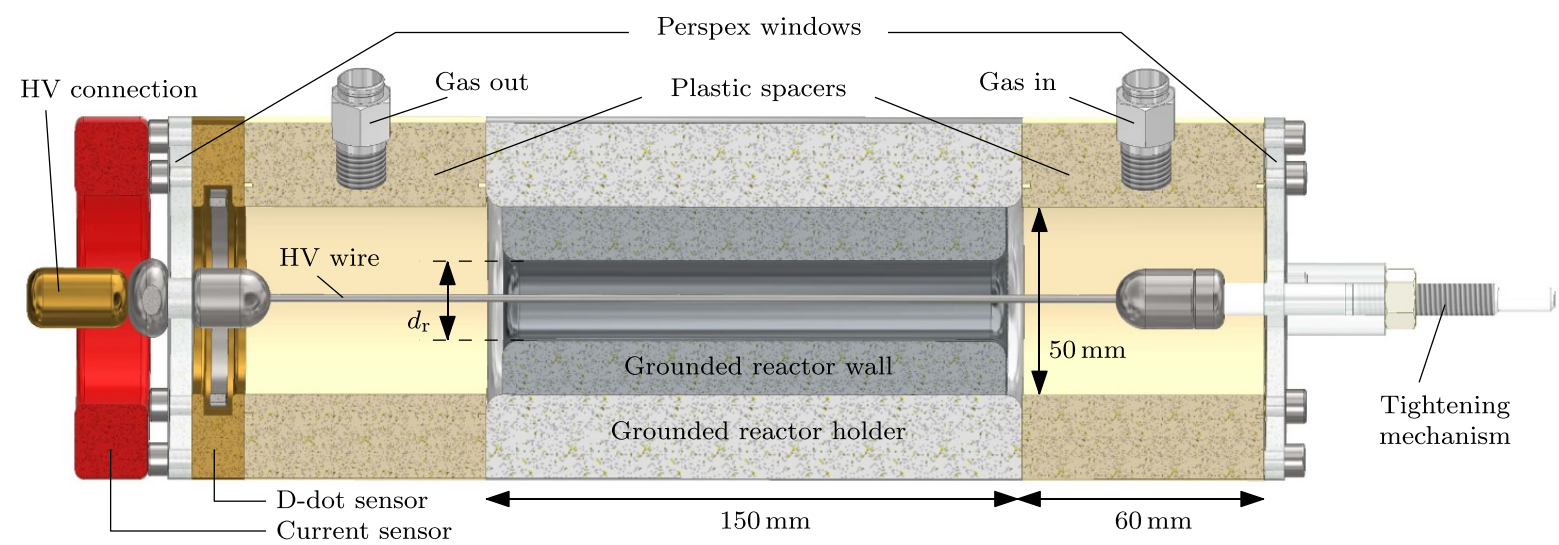

Figure 7. Cut-away drawing of the plasma reactor and peripherals. The grounded plasma reactor is fixed inside a metal plasma reactor holder, which facilitates placing of differently-sized plasma reactors. More details on this structure can be found in figure 8 . A HV wire (not drawn to scale) is held in place by a tightening mechanism inside the plasma reactor. The HV wire is connected (on the left side) to the solid-state IMG. At this connection point a current sensor and D-dot sensor are placed for electrical measurements. Gas connections complete the setup.

at a pulse repetition rate of over $1 \mathrm{kHz}$, but was used at $100 \mathrm{~Hz}$ for all experiments in this paper.

The pulse source is connected to the plasma reactor via resistor $R_{1}$ which acts as a current-limiting resistor. It has a relatively low value of $30 \Omega$ to limit the current in case of a shortcircuit to slightly over $300 \mathrm{~A}$, which is the maximum current the pulse source can withstand (for a short time). During normal operating conditions, the maximum current supplied to the plasma reactor is around $10 \mathrm{~A}$, causing only a small voltage drop over the resistor. Since we measure the pulse voltage after the current-limiting resistor, the resistor has no influence on the discharge energy measurements.

\subsection{Electrical diagnostics}

The voltage in the plasma system is measured with a D-dot sensor [48, 49] and the current with a $200 \mathrm{MHz}$ Magnelab CTF0.5-S current monitor. These sensors are installed around the high-voltage connection in the plasma reactor (see figure 7). The D-dot sensor measures the derivative of the displacement field associated with the voltage and consists of a ring electrode soldered to a SMA connector and mounted into a grounded body.

The sensor signals are measured with an oscilloscope (350 MHz bandwidth LeCroy Wavesurfer 3034) placed in a shielded cabinet for disturbance-free measurements. A passive integrator mounted on the oscilloscope integrates the measured D-dot waveform and thereby reconstructs the actual voltage waveform. The main advantages of using this type of sensor is that the signal-to-noise ratio is excellent and that it is non-intrusive to the system (it has little to no impact on the high-voltage waveform). The disadvantage of this sensor is that low-frequency components of the signal cannot be measured and that waveform reconstruction and calibration has to be carefully done. However, the pulses to be measured have no significant low-frequency content and the waveform reconstruction and calibration can be done with little error. Therefore, the advantages far outweigh the disadvantages. A more detailed description of this type of sensor system can be found in [50, chapter 2].

The power $P(t)$ and energy $E(t)$ are calculated from the voltage $\left(V_{\mathrm{D}}(t)\right)$ and current $(I(t))$ waveforms using the following equations:

$$
\begin{gathered}
P(t)=I(t) V_{\mathrm{D}}(t), \\
E(t)=\int_{0}^{t} P(\tau) \mathrm{d} \tau,
\end{gathered}
$$

after synchronizing $V_{\mathrm{D}}(t)$ with $I(t)$ by means of the capacitive current. The end value of the energy waveform is used for the calculation of the ozone yield (see section 3.5).

\subsection{Plasma reactor and gas handling}

Figure 7 shows a cut-away drawing of the plasma reactor that we used and figure 8 shows a 3D drawing for better understanding of the positioning of the plasma reactor inside the setup. The D-dot sensor and the current sensor are mounted at the left side of the reactor setup at the high-voltage connection to the pulse source. A large metal grounded reactor holder is bolted (with eight long metal bolts each, see figure 8 bottom) in between two plastic spacers that hold the gas connections. In this reactor holder we can mount plasma reactors of different diameter and shape. For this paper we used a U-shaped reactor (see figure 8) so that we can image the streamer discharge through a Perspex window (shown in figure 8, but not in figure 7) in the reactor holder. We used U-shape reactors because they closely resemble the cylinder-wire reactors that we normally use, while still being able to view the discharge. We used similarly-shaped reactors in [51] and showed in [52] that the behavior of these U-shaped reactors is very similar to the regular cylinder-wire reactors of the same diameter. The $\mathrm{U}$-shaped reactor we used in this paper has a diameter $d_{\mathrm{r}}$ (see figure 7) of $16 \mathrm{~mm}$ (with a $0.1 \mathrm{~mm}$ diameter stainless-steel HV wire). 

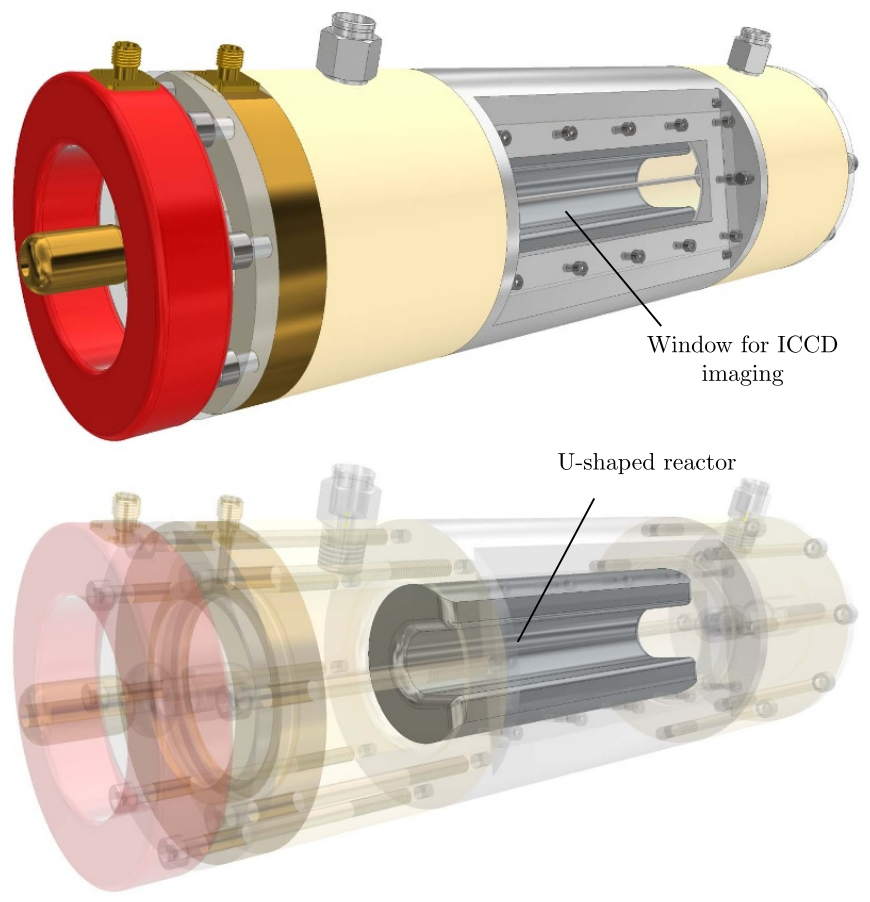

Figure 8. Top: 3D drawing of the setup of figure 7, showing the window for ICCD imaging. Bottom: see-through drawing to clearly indicate how the U-shaped reactor is positioned in the setup. The opening of the reactor is placed perpendicular to the window for ICCD imaging.

The gases we used for the experiments were dry air (purity 5.5) and nitrogen (purity 5.0). Both gases are fed into the plasma reactor with Bronkhorst F-201AV-50K mass-flow controllers. We used a gas flow rate of $21 \mathrm{~min}^{-1}$ in all experiments.

\subsection{ICCD imaging}

For the imaging of the streamer discharge we used a Stanford Optics 4-Picos ICCD camera with a resolution of $580 \times 780$ pixels with a Sigma $180 \mathrm{~mm}$ Macro lens attached (set at an aperture of 5.6). The camera is triggered by the FPGA to ensure that the voltage waveform and the images taken by the camera are synchronized to within $1 \mathrm{~ns}$. The camera is placed in a shielded cabinet and is connected to the laptop via USB over optic fiber to ensure disturbance-free measurements.

An example of a long exposure image is shown in figure 9. The colormap and intensity scale used for this image was used for all images in the paper, so all images can be directly compared to each other. In the figure we see a $150 \mathrm{~ns}$ exposed image when a $9 \mathrm{kV}, 80 \mathrm{~ns}$ pulse is used in nitrogen in the $16 \mathrm{~mm}$ reactor. The high-voltage wire and grounded reactor wall are shown, as well as the colormap we used for all the images in this paper. While such long-exposure images give a good overview of the entire discharge, any temporal information is lost. Therefore, for the analysis of the streamer propagation we mainly use short-exposure images.

Figure 10 shows an example short-exposure image (at the same settings as the long-exposure image in figure 9) and the procedure with which we treat the raw data afterwards. For

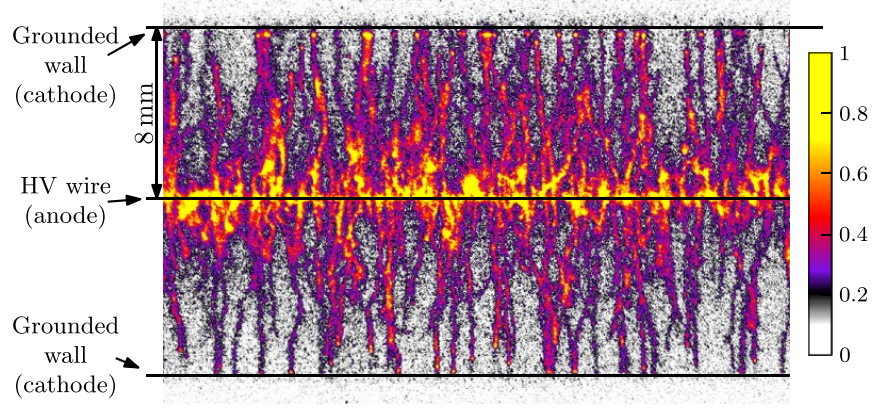

Figure 9. An example long-exposure image, with the grounded reactor wall and $\mathrm{HV}$ wire indicated. The colormap and intensity scale used in this figure is used for all images in this paper.

Experimental settings: $6.8 \mathrm{~ns}$ rise-time pulse from figure 5 (a) at a repetition rate of $100 \mathrm{~Hz}, 21 \mathrm{~min}^{-1} \mathrm{~N}_{2}$ gas flow, $150 \mathrm{~ns}$ ICCD gate width at a gain (multichannel plate (MCP)) voltage of $850 \mathrm{~V}$.

every experimental setting we took 100 images at an exposure time of $3 \mathrm{~ns}$ for at least 25 camera delay settings in $3 \mathrm{~ns}$ steps to capture the start of the discharge until the high-voltage pulse decreases. For every image an algorithm in post-processing (we used MathWork's MATLAB) cuts out the upper half of the image and finds the streamer head that propagated the furthest towards the reactor wall. We only take this furthest streamer head of each image to calculate the streamer length for a certain experimental setting to ensure that we always use the streamer-length data from streamers that propagate in the plane of focus. After this determination, the streamer head position for all 100 images is averaged and the 100 cut-out images are averaged as well. A slice from the middle of the reactor is then used to display the streamer propagation at that experimental time setting. These slices are used in images like figure 13 where we can in one figure see the (averaged) temporal evolution of the discharge.

\subsection{Ozone measurements: UV absorption spectroscopy}

While we are interested to see whether we can control the streamer propagation with the arbitrary waveforms, we are also always trying to maximize the radical-generation yield of our plasma systems. Therefore, to compare our results with other plasma systems and to compare between different experimental settings in our measurements, we measure the ozone yield. It is generally understood that to assess the oxygenradical-generation performance of a plasma this ozone yield (in $\mathrm{g} \mathrm{kWh}^{-1}$ ) is a good indicator, where the highest values in literature are around $200 \mathrm{~g} \mathrm{kWh}^{-1}$ in air $[14,16,17]$.

We measure ozone with the UV-absorption-spectroscopy method that we used in [53], where it is explained in more detail. It consists of a Mikropack DH-2000 UV light source, optical fibers that connect to a gas cell with UV lenses and a spectrometer to measure the plasma-on and plasma-off spectrum. From the UV absorption we then calculate the line-ofsight integrated ozone concentration using the Lambert-Beer law and absorption coefficients from a database. 


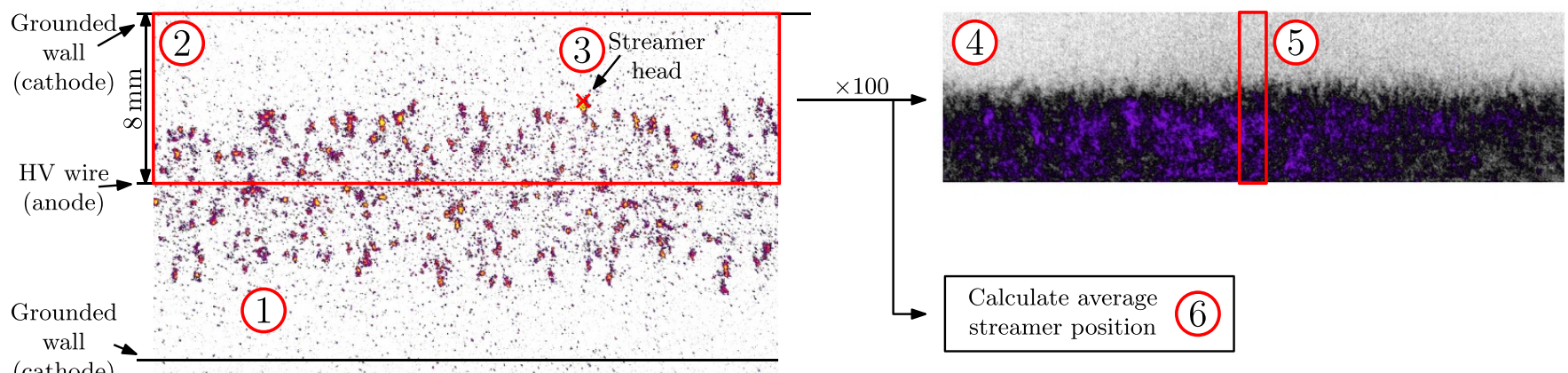
(cathode)

Figure 10. The procedure to obtain the streamer position and an averaged image slice. (1) A single, 3 ns exposure is captured. (2) The area above the HV wire is isolated for analysis. (3) The isolated area is scanned for the longest streamer. (4) The process is repeated 100 times and the isolated areas are averaged. (5) A thin slice is isolated for display (see e.g. figure 13). (6) The 100 calculated streamer positions are averaged. Experimental settings: $6.8 \mathrm{~ns}$ rise-time pulse from figure 5(a) at a repetition rate of $100 \mathrm{~Hz}, 21 \mathrm{~min}^{-1} \mathrm{~N}_{2}$ gas flow, $3 \mathrm{~ns}$ ICCD gate width, 42 ns delay at a MCP voltage of $1000 \mathrm{~V}$.

The ozone-yield calculation is then given by:

$$
G_{\mathrm{O}_{3}}=\frac{C_{\mathrm{O}_{3}} \times \mathrm{FWO}_{3} \times 3.6}{V_{\mathrm{m}} \varepsilon},
$$

where $G_{\mathrm{O}_{3}}$ is the ozone yield (in $\mathrm{g} \mathrm{kWh}^{-1}$ ), $C_{\mathrm{O}_{3}}$ is the ozone production (in ppm), $\mathrm{FWO}_{3}$ is the formula weight of ozone $\left(48.00 \mathrm{~g} \mathrm{~mol}^{-1}\right), V_{\mathrm{m}}$ is the molar volume $\left(24.51 \mathrm{~mol}^{-1}\right.$ at room temperature and atmospheric pressure) and $\varepsilon$ is the energy density (in $\mathrm{J}^{-1}$ ) which is defined as:

$$
\varepsilon=\frac{f_{\mathrm{rr}} E_{\mathrm{p}} \times 60}{F},
$$

where $E_{\mathrm{p}}$ is the total dissipated energy per pulse (in $\mathrm{J}$ ) by the plasma, $F$ is the gas flow rate (in $1 \mathrm{~min}^{-1}$ ) and $f_{\text {rr }}$ is the repetition rate of the pulse source (in $\mathrm{Hz}$ ). The values for $C_{\mathrm{O}_{3}}$ were obtained when the ozone concentration settles, which was after around $5 \mathrm{~min}$.

\section{Results and discussion}

Since the main goal of this work was to investigate how we can control the streamer propagation with arbitrary waveforms and what effect this has on ozone yields, we used air and nitrogen because we expect that we can observe streamer control better in nitrogen. We performed ozone measurements and analyzed the streamer propagation as a function of rise time and as a function of the shape of the rising edge of the high-voltage pulse.

\subsection{Discharge current determination}

Figure 11 shows example measurements when plasma is generated in the plasma reactor. From the measurement results we calculated the capacitive current $I_{\text {cap }}(t)$ by differentiating the voltage waveform and multiplying with the calculated reactor capacitance $C_{\text {reactor }}$ (calculated with a measurement at low voltage with no discharge inception):

$$
I_{\text {cap }}(t)=C_{\text {reactor }} \frac{\mathrm{d} V_{\mathrm{D}}(t)}{\mathrm{d} t} .
$$

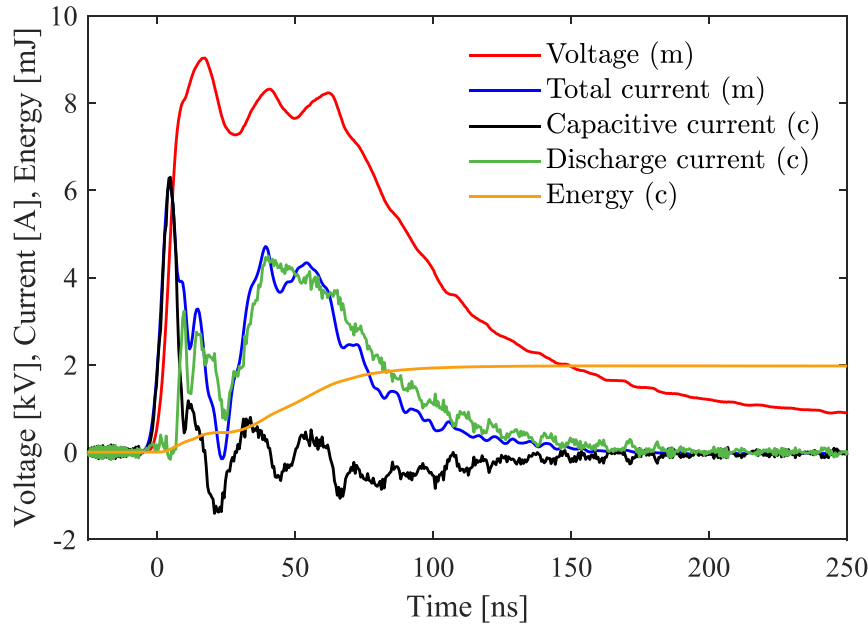

Figure 11. Example waveforms in the plasma system. The (m) in the legend denotes measured data and a (c) calculated data. Experimental settings: $6.8 \mathrm{~ns}$ rise time $80 \mathrm{~ns}$ pulse at a repetition rate of $100 \mathrm{~Hz}$ at $21 \mathrm{~min}^{-1}$ synthetic air gas flow.

The discharge current $I_{\text {discharge }}(t)$ can then be calculated with:

$$
I_{\text {discharge }}(t)=I(t)-I_{\text {cap }}(t) \text {. }
$$

As we can see in figure 11, the total current shows a capacitive current during the rising edge of the pulse. The discharge current then adds to this peak. This current consists of two parts. Before $30 \mathrm{~ns}$ there is a short peak, followed by a significant increase after $30 \mathrm{~ns}$. We will see in the next section that these two different phases are first the crossing of the streamers from the wire to the wall of the reactor, followed by a phase with a glow around the wire (the secondary streamer phase, as we will describe in the next section). The current associated with this second phase contributes for a large part to the total dissipated energy in the plasma (since the gap is bridged by a conductive channel after the primary streamer has reached the cathode). 


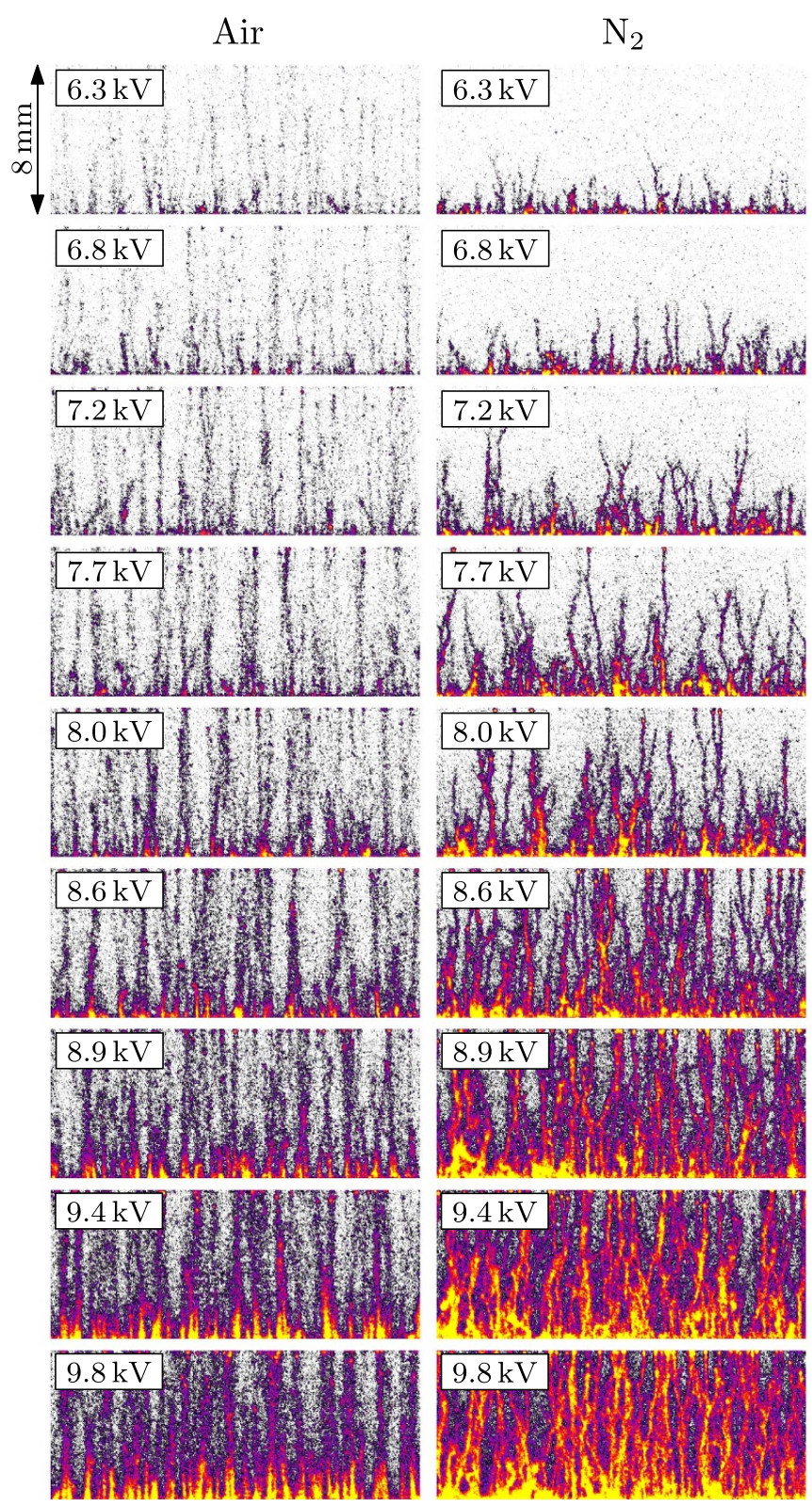

Figure 12. Long exposure images of the discharge in air (left) and nitrogen (right) as a function of voltage. The images are cut out of the top half of full long-exposure images (see figure 9) and show the high-voltage wire on the bottom and the grounded reactor wall at the top. For these experiments, the gas flow was $21 \mathrm{~min}^{-1}$, the $6.8 \mathrm{~ns}$ rise time, $80 \mathrm{~ns}$ pulse duration pulse was used at $100 \mathrm{~Hz}$ pulse repetition rate, the ICCD MCP voltage was $850 \mathrm{~V}$ for all images using an ICCD gate width of $150 \mathrm{~ns}$.

\subsection{Streamer imaging: rise time variation}

Since we are applying only positive high-voltage pulses to the wire (anode), we observe cathode-directed (positive) streamers emerging from the wire towards the outer wall of the reactor (cathode). Figure 12 shows long-exposure images of the streamer discharge, both in air and nitrogen, for different voltages at the fastest rise-time setting $(6.8 \mathrm{~ns})$. Generally, increasing the voltage leads to longer and more intense discharge channels due to the higher energy input. However, three main differences in the discharge structures are apparent, which depend on the working gas: I. The streamers in nitrogen feature a higher optical emission intensity, i.e. they appear brighter. II. The streamers in nitrogen feature more branching channels, i.e. in air the channels are almost straight. III. The maximal streamer length is much shorter in nitrogen for voltages below $8 \mathrm{kV}$, i.e. in air the gap is already bridged at lower voltages.

The majority of the optical emission in non-thermal plasmas in nitrogen-oxygen mixtures is due to the so-called second positive system of nitrogen (SPS, $\mathrm{N}_{2}\left(C^{3} \Pi_{\mathrm{u}}\right) \rightarrow \mathrm{N}_{2}\left(B^{3} \Pi_{\mathrm{g}}\right)$ ) [54]. Consequently, the first result, i.e. the lower emission intensity of the discharge channels in air compared to nitrogen can be explained by the effective collisional quenching of the SPS by oxygen, which significantly lowers the density of $\mathrm{N}_{2}\left(C^{3} \Pi_{\mathrm{u}}\right)$ and thereby reducing the photon emission [55]. This was also reported for point-to-plane streamer discharges, e.g. in $[56,57]$.

The second observation (more branching in nitrogen) is also well-known [56, 57], and is often connected to the stronger photo-ionization air compared to nitrogen. The presence of photo-ionization attenuates the required electric field enhancement needed for the streamer propagation and thereby smooths the electron distribution in front of the streamer head [58], since branching occurs when the electron density in front the streamer head features a local disturbance [59].

The third finding (shorter streamer length in nitrogen at lower applied voltages) can be explained by the different stability (electric) fields required for streamer propagation in nitrogen and air. The maximal streamer length is connected to this stability field, which is defined by the voltage drop over the streamer length [2], i.e. it defines the electric field strength needed to sustain the streamer propagation. As stated before, this E-field strength has to be higher in nitrogen due to the lack of photo-ionization. Consequently, at the same applied voltage the streamer channels in nitrogen are shorter, especially for low applied voltages, i.e. when the voltage rise stops, the streamer propagation stops, too. Additionally, the tendency to branch further reduces the maximal streamer propagation length in nitrogen.

Generally, we have to be aware that due to the used wire-tocylinder arrangement, we underestimate the maximal streamer length, i.e. we only see streamer crossing the gap, which propagate in the area perpendicular to the line-of-sight of the measurement at the position of the wire. The discharge arrangement geometry plays also a role when comparing our results with literature, since most fundamental studies were performed in pin-to-plate arrangements, with single or multiple streamers starting from one tip. In our experiments, however, multiple streamers propagate simultaneously from the central wire and will influence each other, e.g. via the electric field. This we have to keep in mind for the following analysis of the spatio-temporal discharge development.

Figure 13 shows this for discharges in both air and nitrogen for the three different rise times and figure 14 shows the corresponding calculated streamer head positions. The images in figure 13 consist of slices of $3 \mathrm{~ns}$ exposed and averaged (over 100 images) images from the middle of the reactor and also 

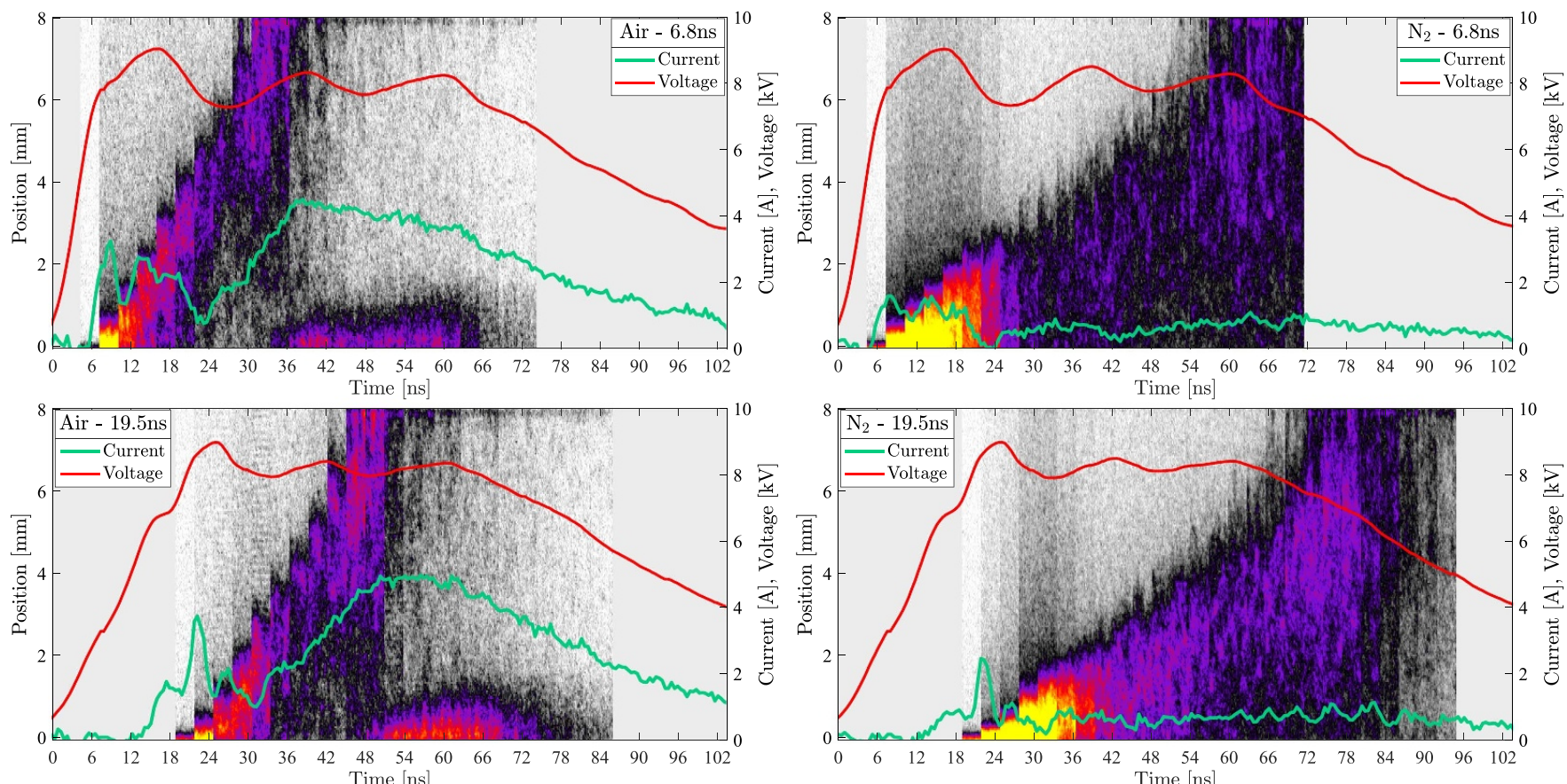

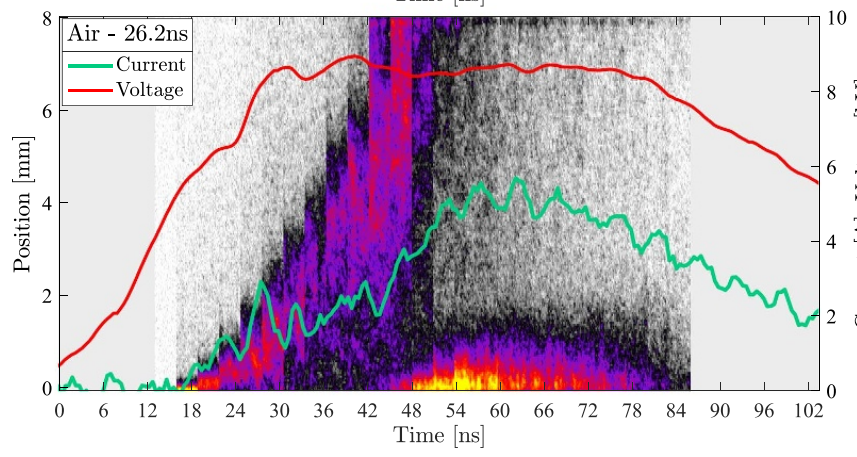

(a)

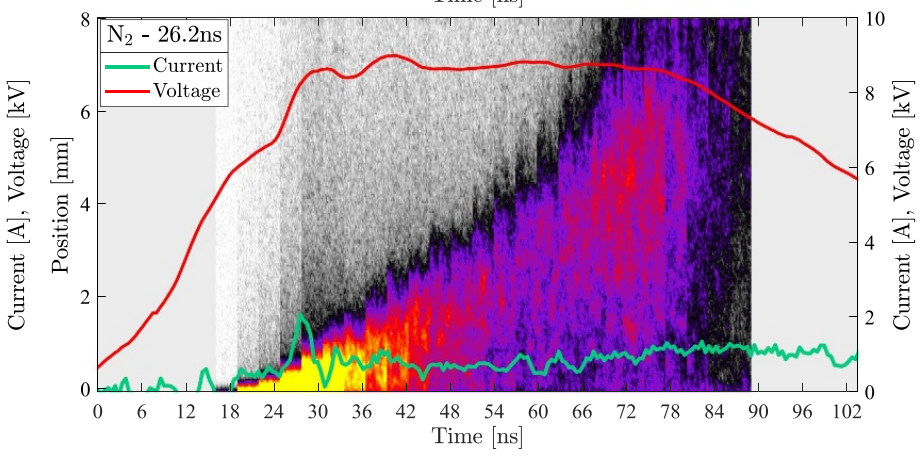

(b)

Figure 13. Propagation of the streamers as a function of time and space for the three different rise times (a) air and (b) nitrogen. Each image consists of slices of $3 \mathrm{~ns}$ gated and averaged (over 100 single shots) images from the middle of the reactor (see figure 10). For ease of interpretation the voltage and discharge current (both averaged over 100 waveforms) are also plotted. For these experiments, we used a 2 $1 \mathrm{~min}^{-1}$ flow of synthetic air and ran the pulse source at a repetition rate of $100 \mathrm{~Hz}$ and a pulse duration of $80 \mathrm{~ns}$.

show the synchronized voltage and discharge current. In the images, two distinct phases can be distinguished for air. First, streamers originate from the anode and propagate towards the cathode in 20-25 ns. After the streamers have bridged the gap a glow appears near the anode. We refer to these two phases as the primary streamer phase and the secondary streamer phase respectively [60].

What we can also observe in figure 13 is that the propagation of the streamers appears to be almost identical for each rise-time setting, except that for the two longer rise times the start of the discharge is delayed by about $14 \mathrm{~ns}$. This can also be seen in figure 14, where the results of the longest rise times appear to be nearly identical. Comparing the discharge current and the discharge development, it is evident that both for air and nitrogen the first discharge current is connected to the primary streamer inception, which is delayed for the slower rise times. Generally, the shape of the voltage waveform can be recognized in the discharge current, especially visible for the dip after the first voltage peak after the slope for the fastest voltage rise time.

The secondary streamer phase appears to be a bit more intense for longer rise times in air. This is because we maintained a constant peak voltage for all these measurements, which means that the stable plateau voltage of the slowest pulse is a bit higher (because the shorter the rise time, the higher the overshoot on the voltage). Furthermore, for the fastest rising pulse the secondary streamer phase starts earlier than for the slowest two rise times. However, the voltage of this fastest pulse also starts decreasing at a more rapid rate than the slower pulses, because by shifting the delay of the IMG stages to generate the slower pulses we did not change the total pulse duration of each stage. Despite this, there are just small variations in the duration and the extend in the volume (about $1 \mathrm{~mm}$ ) of the secondary streamer phase for each rise time.

For the discharge in nitrogen, no secondary streamer phase occurs, since the streamers propagate more slowly and 


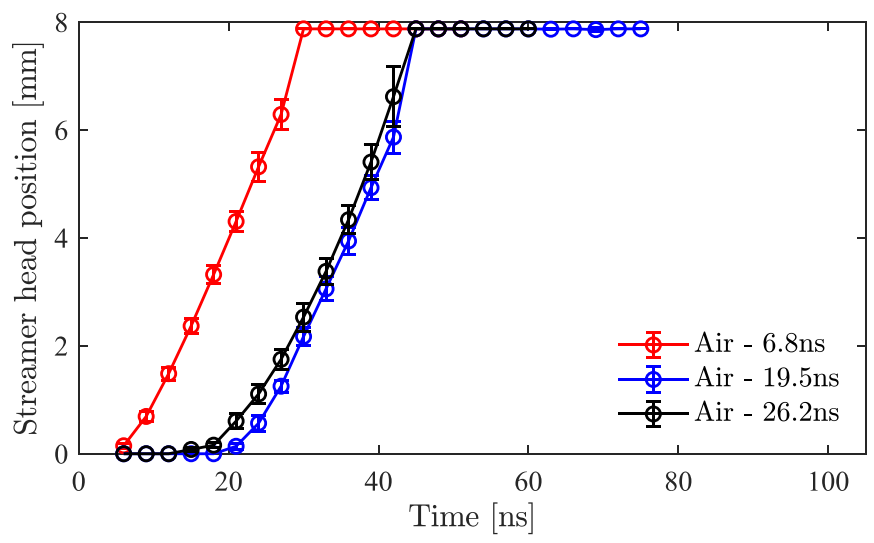

(a)

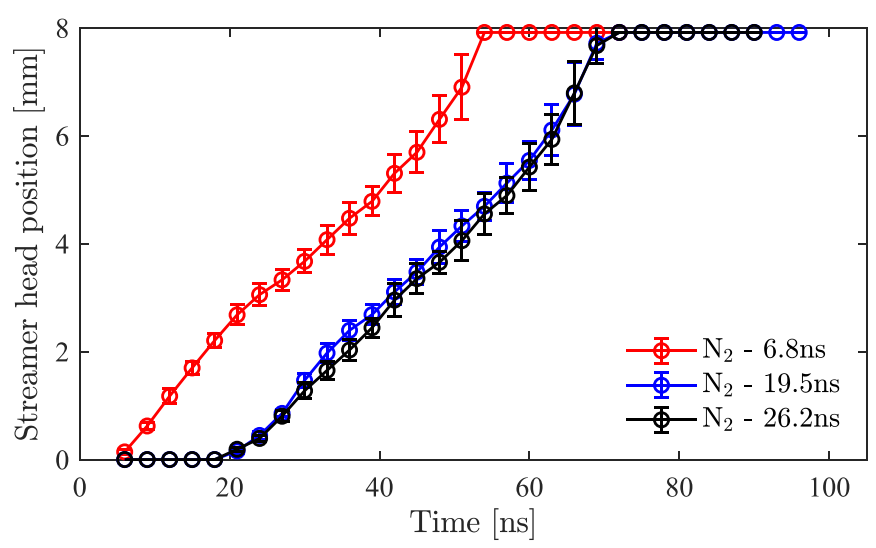

(b)

Figure 14. The calculated streamer head positions from the data of figure 13 for (a) air and (b) nitrogen. The error bars represent the standard deviation on the streamer position calculation.

therefore only reach the electrode as the pulse is almost starting to decrease in amplitude again. The streamer inceptions start at slightly lower voltages and consequently lower electric field strength. Because there is no significant secondary streamer phase in nitrogen, the energy dissipated by the discharge is also on average around four times lower as compared to the discharge in air. This difference is also apparent when comparing the discharge current and the transferred charge between air and nitrogen, see table 1 (at the end of the paper) for the values of the quantities mentioned in this paragraph.

4.2.1. Streamer velocity. Many researchers have reported on streamer propagation velocities for a range of voltages and rise times for pulsed discharges. It is generally found and understood that a higher applied electric field increases the streamer propagation velocity and that the velocities are in the range of $10^{5}-10^{6} \mathrm{~m} \mathrm{~s}^{-1}[25,51,56,57,61-66]$. Besides the applied voltage amplitude, the rise rate of the applied voltage also influences the streamer propagation velocity in single-filament DBDs [31]. Most studies found that the velocity increases when the rise rate increases $[24,51,56,61,67-70]$. This effect was explained by the fact that streamers initiate while the highvoltage pulse still rises and therefore start at a lower voltage

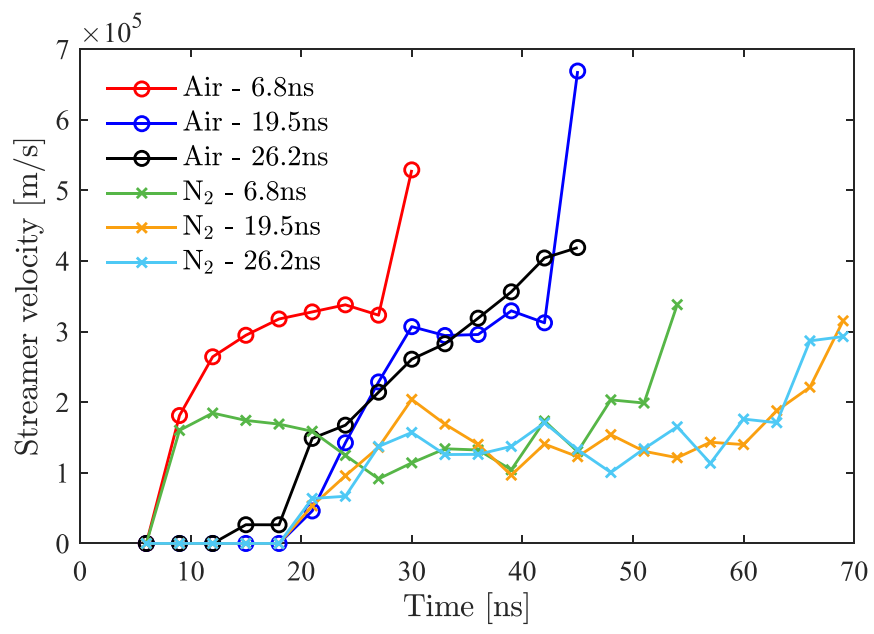

Figure 15. The calculated streamer velocities from the data of figure 14 for air and nitrogen. For readability, error bars were omitted in this figure.

when the rise rate is low. Additionally, for pulses with (sub-) nanosecond rise times, the applied voltage rises on the same time scale as the streamer propagation, which further boosts the streamer movement.

Figure 15 shows the calculated streamer velocities from our own experiments. These velocities were calculated simply as the derivative of the streamer head position results. For each experimental setting, the velocity typically first shows a jump when the streamers have just initiated, followed by a relatively stable plateau and then finally by another jump when the streamers connect to the ground electrode. The first jump is simply from the fact that the streamer velocity starts from zero and then once the streamers are formed they propagate under their own electric field during the majority of the time while crossing the gap. Since the streamers are (weakly) ionized channels, they transport the voltage potential of the high-voltage wire to the streamer head and when this head approaches the grounded wall of the reactor, the electric field in front of the streamer head increases significantly, causing the final jump in velocity. That the final jump is not relatively the same for each setting (e.g. compare Air 19.5 ns and Air $26.2 \mathrm{~ns}$ ) is that we chose the delay steps between each image ( $3 \mathrm{~ns}$ ) on a fixed time base (and not that time zero coincides with the start of the streamers for each setting), so the streamer arriving at the grounded wall does not coincide exactly on the resolution of this time base for all settings.

From the velocity results we can conclude that the velocities in air during the stable propagating region in the middle of the reactor are roughly twice that of nitrogen (approximately $3 \times 10^{5} \mathrm{~m} \mathrm{~s}^{-1}$ vs. $1.5 \times 10^{5} \mathrm{~m} \mathrm{~s}^{-1}$ ). Typically, results in air and nitrogen do not show such a large difference (e.g. $[56,57]$ ) but like before we have to remark that our discharge arrangement is significantly different (cylinder-to-wire vs. point-to-plane) and electric field screening by neighboring propagating streamers likely play a big role in the streamer propagation in our reactor. Likewise, our results as a function of rise time do not match with previously reported results 
(e.g. $[24,51,56,61,67-70])$, where most people found an increase in streamer velocity with an increase in rise rate. To further analyze this mismatch, we will perform additional experiments for different levels of background ionization (e.g. by changing the pulse repetition rate), voltage amplitudes, pulse durations, etc for our wire-to-cylinder arrangement and for specific conditions in direct comparison in a point-to-plane arrangement. Additionally, our solid-state IMG development is heading for shorter pulses (20 ns) and higher voltages (30 $\mathrm{kV}$ and higher), which extends the parameter range and will e.g. most-likely generate the secondary streamer phase for nitrogen.

\subsection{Streamer imaging: rising edge shape variation}

As we saw in the previous subsection, changing the rise time of the pulse did not significantly change the streamer propagation results in our discharge arrangement other than increasing the streamer inception delay and slightly increasing the inception voltage for the shorter rise times. In this section, we investigate what effect a step-like shape of the rising edge has on the streamer propagation both for air and nitrogen. We applied these waveforms with different step heights and about $9 \mathrm{kV}$ overall amplitude (see figure 5(b)) to the same discharge arrangement as before. The spatio-temporal discharge development together with voltage and discharge current, the corresponding streamer head positions as function of time and the calculated streamer velocities are shown in figures 16-18.

For steps below $4 \mathrm{kV}$ (4S.40D and 5S.40D for both air and nitrogen, figure 16) we obtain similar results as before: the streamer propagation is similar to the regular $6.8 \mathrm{~ns}$ rise time pulse, but with a delay corresponding to the duration of the plateau until the voltage rises again. This means that the electric field strength during the initial step is not high enough to start the discharge. Furthermore, it indicates that the charge carriers generated during this pre-breakdown phase (about $40 \mathrm{~ns}$ duration with this applied voltage) do not effect the subsequent streamer initiation and propagation, although the electric field strength at the streamer inception is slightly higher compared to the regular $6.8 \mathrm{~ns}$ rise time pulse (both for air and nitrogen, see table 1 for the values). Additionally, the secondary streamer phase for air is shorter $(\approx 20$ ns vs. $\approx 35$ ns) and weaker in emission intensity as well as extension into the volume as compared to the regular $6.8 \mathrm{~ns}$ rise time pulse. This is due to the already declining applied voltage after the streamer has crossed the gap for the steps 4S.40D and 5S.40D, which is most likely the reason why the discharge energies are slightly lower for these two steps compared to the regular 6.8 ns rise time pulse, while the transferred charge slightly higher, see table 1 . The higher transferred charge is a consequence of the slower decay of the applied voltage for the step-like voltage waveforms, see figure 19. The discharge currents for 4S.40D and 5S.40D in air (figure 19) feature a lower initial peak corresponding to the start of the streamer propagation compared to the regular $6.8 \mathrm{~ns}$ rise time pulse, but the current maximum during the secondary streamer is the same as for the regular pulse, but with shorter plateau, which leads to the lower energy input as described above.
For nitrogen, we found the same behavior for the 5S.40D case in comparison to the regular 6.8 ns rise time pulse, i.e. similar (but delayed) propagation velocities (see figure 18), consumed energy, and transferred charge, while only the discharge inception voltage is a bit higher (see table 1). For the 4S.40D pulse (higher initial step than 5S.40D), the velocity, energy, and charge are all somewhat lower compared to the $5 \mathrm{~S} .40 \mathrm{D}$ case. That is most likely a consequence of the less steep rise of the applied voltage after the initial step (see figure 16(b)), which means lower energy input after the streamer inception. However, when the voltage during the initial step is higher than the inception voltage (i.e. above $5 \mathrm{kV}$ ), the streamer propagation starts during the first rising edge of the pulse, but is hindered by the drop of the applied voltage after the initial peak. This is particularly pronounced for nitrogen (figure 16(b) for 3S.40D), where the streamer literally stops propagating - since the stability field is not sustained by the applied voltage anymore-and restarts when the voltages rises again (at $t \approx 40 \mathrm{~ns}$, see also figures 17 and $18(\mathrm{~b})$ ). That demonstrates how step-like voltage shapes can be used to control the streamer propagation in the gap. Interestingly, the long-exposure images of the discharges in figure 20 for the four used step-like voltage waveforms do not feature significant differences, although the emission near the wire is lower compared to the regular $6.8 \mathrm{~ns}$ rise time pulse.

For air the streamer propagation does not stop when the applied voltage drops, but the emission intensity is drastically decreased after the drop, see figure 16(a) for 2S.40D and 3S.40D. That the streamers do not completely stop could also be related to the lower stability field needed for propagation in air. The intensity decrease in the streamer channels (which can also be clearly seen in figure 20) is a consequence of the reduced energy input in the channel, which sustains the streamer propagation. This is also evident when analyzing the discharge current that drops almost to zero for $2 \mathrm{~S} .40 \mathrm{D}$ and $3 \mathrm{~S} .40 \mathrm{D}$, which is not the case for the regular $6.8 \mathrm{~ns}$ voltage pulse (see figure 13(a)). In addition to that we have to consider what a lower intensity means, i.e. since each $3 \mathrm{~ns}$ slide is the average of 100 single shots, a lower intensity is also corresponding to fewer propagating streamers, which can also be seen in the long-expose single shots in figure 20 . These long-exposure images show for air that for the applied voltage pulses with steps high enough to initiate the streamer propagation $(2 \mathrm{~S} .40 \mathrm{D}$ and $3 \mathrm{~S} .40 \mathrm{D})$ have the same features as for lower voltage amplitudes (see figure 12). This can partly be explained by the different energy input in the streamer channel, i.e. for lower voltage amplitudes there is less energy input, which can sustain the propagation. Moreover, the electric field strength during the streamer propagation is also lower for lower voltage amplitudes, which additionally hinders the streamer movement. Although the step-like voltage waveform 2S.40D and 3S.40D finally reach the same overall amplitude (but delayed), the energy input is much lower, see table 1. This can also be deduced from the direct comparison of the discharge current in figure 19 for these two cases, i.e. the currents during the streamer start and the subsequent secondary streamer phase are much lower compared to the regular $6.8 \mathrm{~ns}$ rise time pulse. At least for air, we see that as a clear 

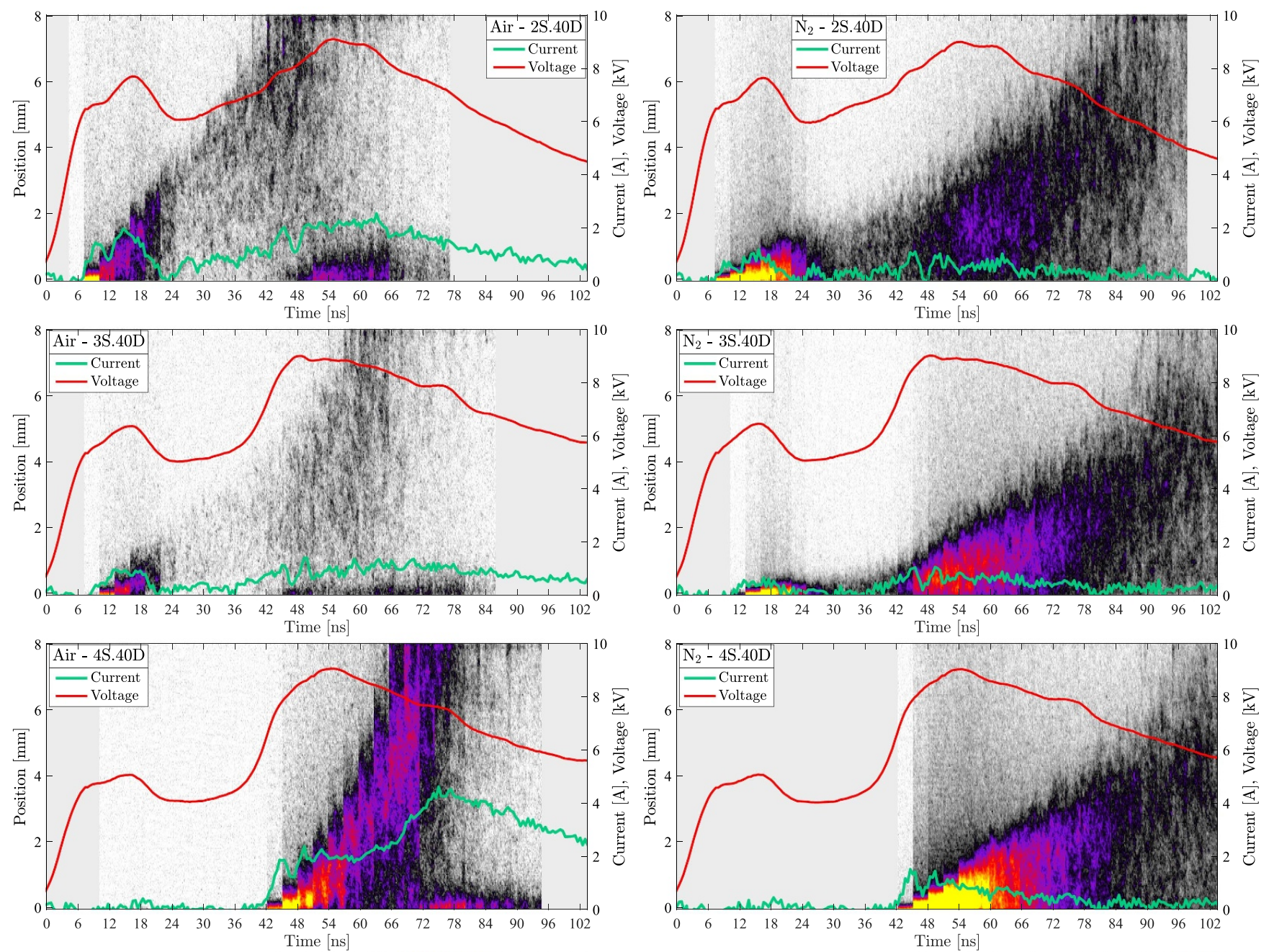

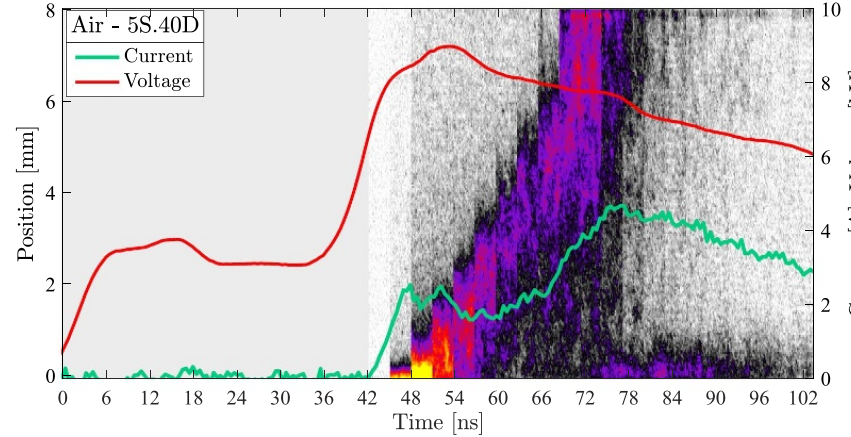

(a)

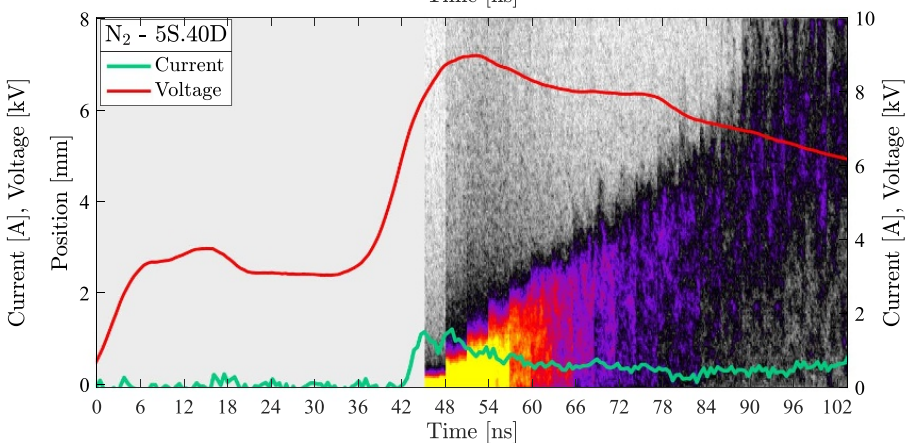

(b)

Figure 16. Propagation of the streamers as a function of time and space for the four different waveforms with different rising edge shape (see figure 5(b)) in (a) air and (b) nitrogen. For ease of interpretation the voltage and discharge current are also plotted. Experimental settings: $21 \mathrm{~min}^{-1}$ gas flow, a pulse repetition rate of $100 \mathrm{~Hz}$ and images processed as described in figure 10 .

indication that the energy input during the primary streamer phase by the rising applied voltage is essential for the streamer propagation.

So in conclusion: changing the rise time of the $80 \mathrm{~ns}$ pulse for air changes little for the streamer propagation and the secondary streamer phase, but by varying the rising edge shape by introducing a step, we can use the IMG to control the secondary streamer phase. Therefore, it is interesting to see what effect this has on the ozone yield, which follows in the next section.

\subsection{Ozone yields}

4.4.1. Rise time variation. Figure 21 shows the ozone results for the rise-time experiments. (The error bars result from the standard deviation on the energy measurements and the 


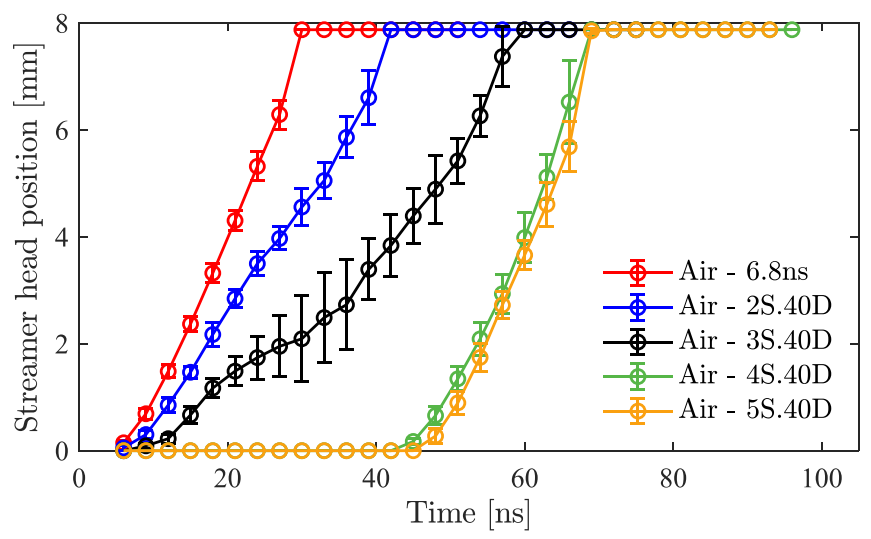

(a)

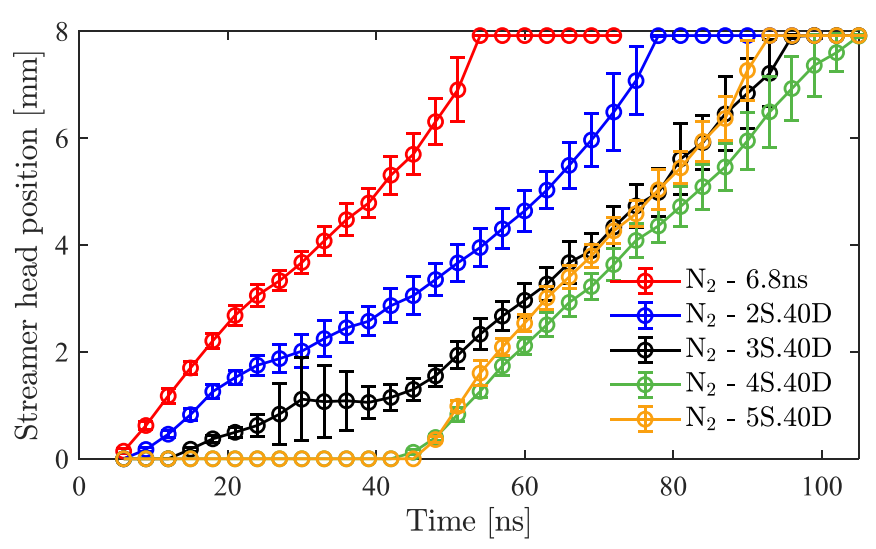

(b)

Figure 17. The calculated streamer head positions from the data of figure 16 for (a) air and (b) nitrogen. As reference, also the results of the $6.8 \mathrm{~ns}$ rise time pulse are plotted.

error on the ozone measurements.) It should be noted here that the voltage on the $x$-axis of figure 21 is the peak voltage of the pulse and not the stable plateau voltage of the pulse. Since the overshoot in the fastest pulse is higher than for the slower pulses (see figure 5(a)) the results are slightly shifted to the right in the figure. We chose this, rather than the plateau voltage, because the propagation results in the images appear to be more influenced by the peak voltage, rather than the plateau voltage. In either case the results of figure 21 show that there is little effect of the rise time on the ozone production and ozone yield (and these effects would be even smaller when the plateau voltage would be used rather than the peak voltage). While the slowest rise time shows the highest ozone concentrations, this is also the waveform that resulted in the brightest secondary streamer phase in figure 13. As described before, this is the result of a slightly higher plateau voltage for this setting. We can also see this in the dissipated energy in the discharge in table 1; it is highest for the longest rise time.

In [14] we clearly found that the rise time of the pulse changes the ozone yield: the shorter the rise time, the higher the ozone yield. The difference between a 0.4 ns rise time and $5.6 \mathrm{~ns}$ rise time was around $50 \%$. This is clearly not the case in our results. However, the pulses are also very different. In [14]

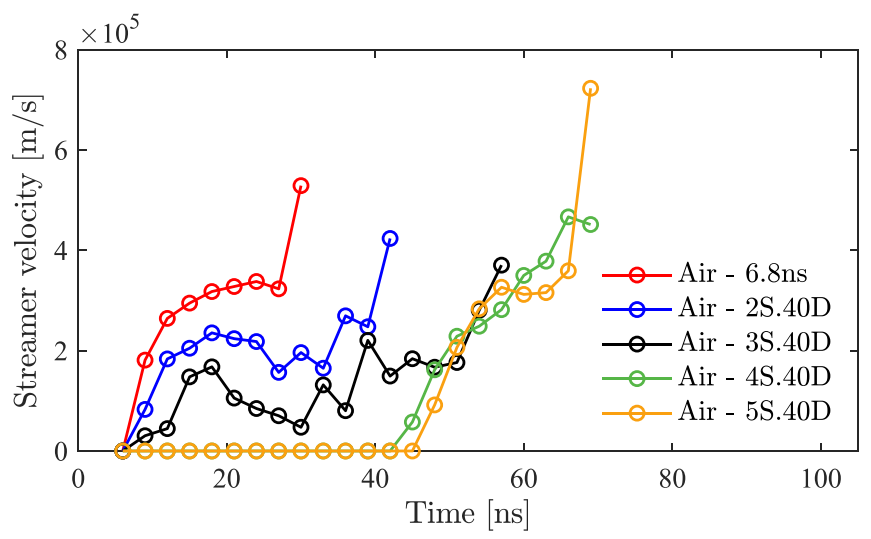

(a)

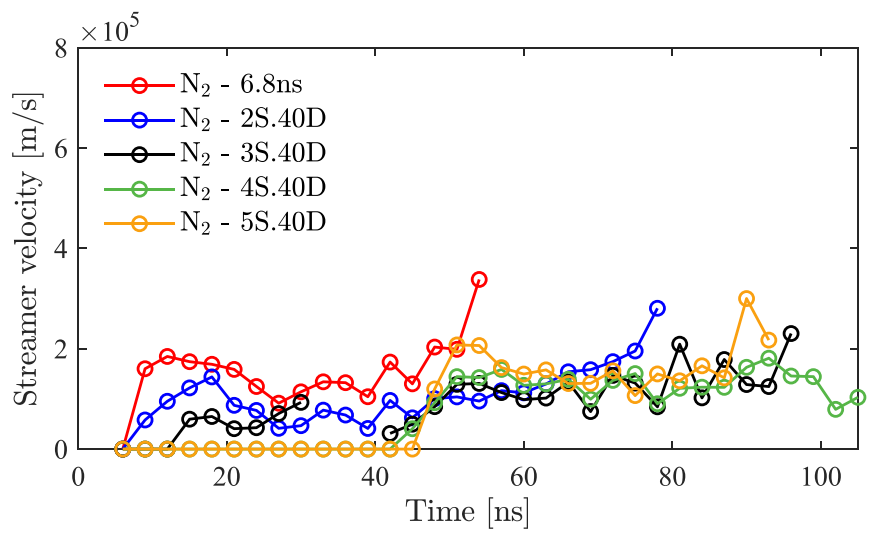

(b)

Figure 18. The calculated streamer velocities from the data of figure 17 for (a) air and (b) nitrogen. For readability, error bars were omitted in this figure.

we used pulses of just 9 ns long and had no clear secondary streamer phase.

The effect of the secondary streamer phase on ozone production is a topic still under discussion. Van Heesch et al [15] and Eichwald et al [71] showed that the oxygen-radical energy yield is lower in the secondary-streamer phase as compared to the primary-streamer phase. However, Ono et al [72] and Komuro et al [73] show that atomic oxygen is mainly (energy efficiently) produced in the secondary-streamer phase, which is in contradiction with the findings of van Heesch et al. Komuro et al claim that the fact that van Heesch et al used moist air instead of dry air (as Komuro et al and Ono et al use) might be a possible reason for this contradiction. Furthermore, they note that in the discharge of Eichwald et al the secondary streamer phase is short compared to the primary streamer (where their own streamers are more than half of the length of the primary streamer) and that therefore the oxygen radical yield of the primary and secondary streamer are much closer. In our discharge the secondary streamers are also short compared to the primary streamer phase (like Eichwald et al and van Heesch et al) and additionally we have a discharge consisting of many parallel streamers (like van Heesch et al), rather than a point-to-plate arrangement (like Ono et al). In any case, this is an important topic that we will surely address in further 


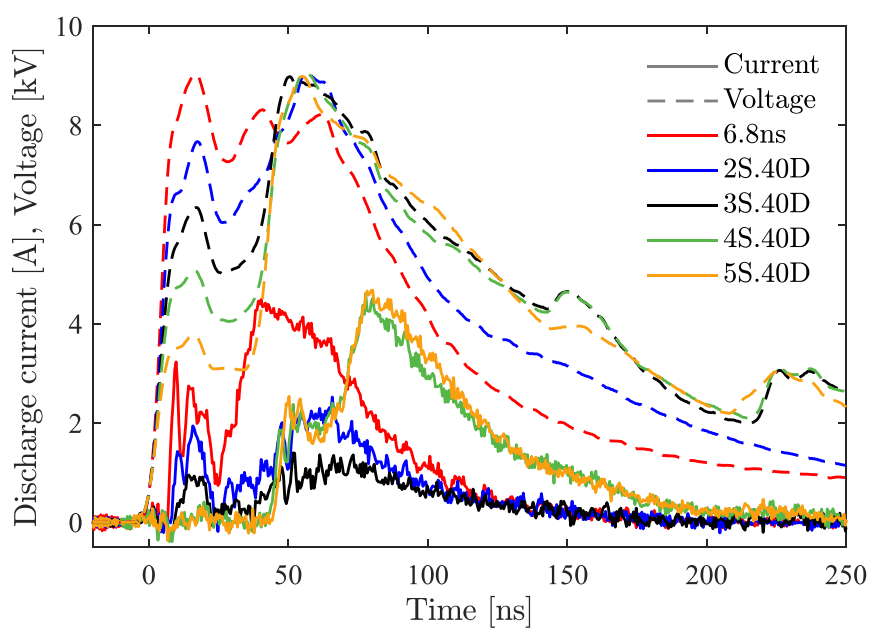

Figure 19. Calculated discharge current as a function of the rising edge shape. For these experiments, we used a $21 \mathrm{~min}^{-1}$ flow of synthetic air and ran the pulse source at a repetition rate of $100 \mathrm{~Hz}$ and a peak voltage of $9 \mathrm{kV}$ for each setting.

research when we have higher voltages and shorter duration pulses available from our solid-state IMGs.

A second observation from the results is that higher applied voltages result in lower yields. This effect is expected, since we operate the streamer discharge also for a large part in the secondary streamer phase. This secondary streamer phase has a resistive character and with increasing the voltage the dissipated plasma energy and therefore the energy density in the plasma reactor increases significantly.

The effect that a higher energy density decreases the ozone yield was also reported in [18, 53, 74-78]. This effect is called discharge poisoning [79] and happens when ozone is generated in air. This process is the result of an increase in the concentration of $\mathrm{NO}_{\mathrm{x}}$ and an increase in the gas temperature with energy density. Both of these effects promote the reaction of ozone with $\mathrm{NO}_{\mathrm{x}}$ and consequently reduce the ozone concentration $[75,76]$.

In conclusion: for our results on rise-time variation there seem to be slight differences in the secondary streamer phase, but it these are not enough to cause any noticeable effect on the ozone yields; only the energy density increase decreases the ozone yields.

4.4.2. Rising edge shape variation. Figure 22 shows the ozone yields for the rising edge shape variation. Instead of plotting the yield as a function of the applied peak voltage, we used the energy density instead, since we discussed earlier that this has a significant effect on ozone yields.

The ozone yield results show that using the 2S.40D and 3S.40D stepped waveforms appear to result in higher ozone yields. These were the settings for which the secondary streamer phase was shortest. However, these are also the results at the lowest energy density, so it might as well be concluded that the higher ozone yields for the stepped waveforms are more an effect of a lower energy density (which promotes less ozone destruction, as we described before) rather than

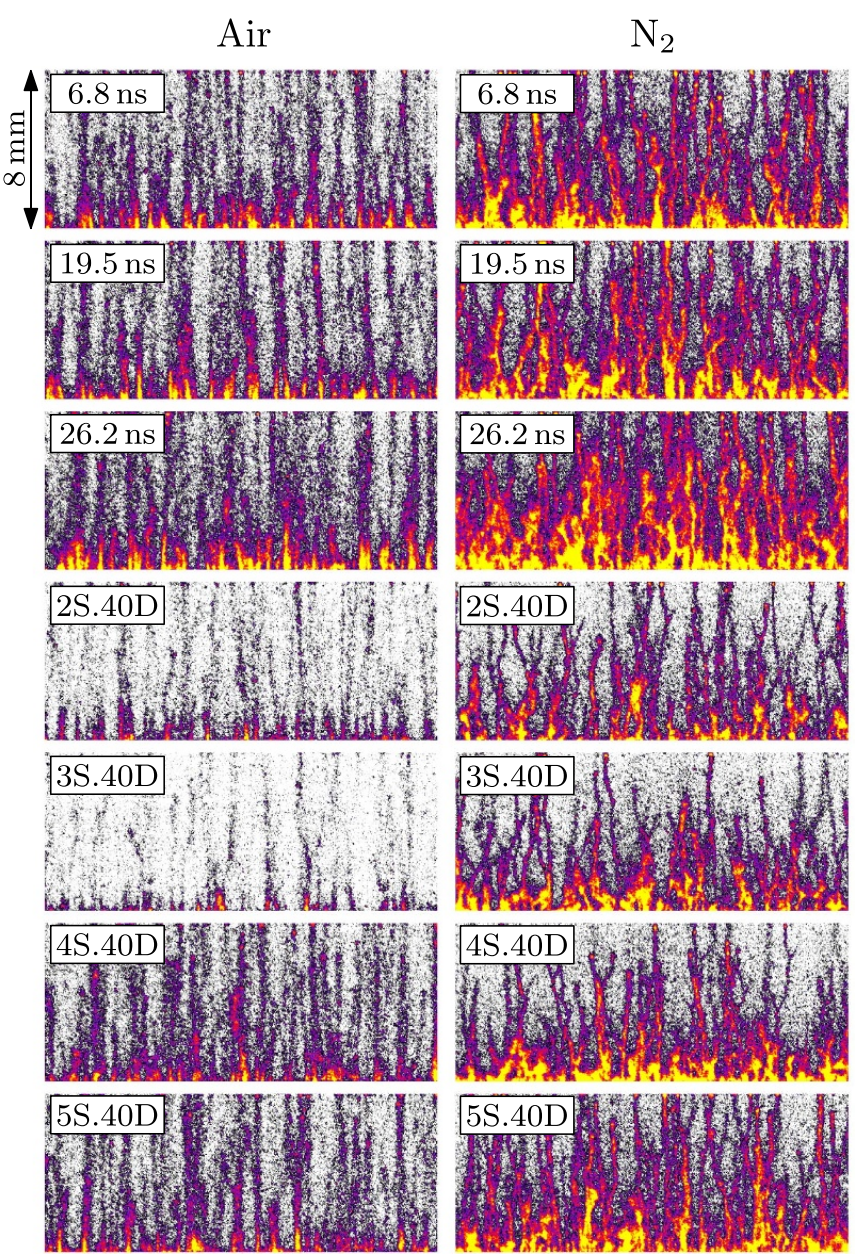

Figure 20. Long-exposure, single shot images of the discharge in air (left) and nitrogen (right) as a function of the waveform shape. The images are cut out of the top half of full long-exposure images (see figure 9) and show the high-voltage wire on the bottom and the grounded reactor wall at the top. For these experiments, the gas flow was $21 \mathrm{~min}^{-1}$, the pulse duration pulse was $100 \mathrm{~Hz}$, the MCP voltage was $850 \mathrm{~V}$ for all images and the exposure time $150 \mathrm{~ns}$.

the duration of the secondary streamer regime for these waveforms. This is an effect that we need to study further once the solid-state IMG can work over a wider range of pulse settings (higher voltages, lower pulse durations, etc). For now we can conclude that the pulse shape can indeed control the streamer propagation to an extent, but that it as of yet has an uncertain effect on the ozone yields.

\subsection{Final thoughts on system optimization}

In general, the ozone yields we achieve in our system are around $65-90 \mathrm{~g} \mathrm{kWh}^{-1}$, which is more than twice as low as with our faster subnanosecond pulse source [14] and similar to the ozone yield in experiments we did with a DBD reactor and a regular solid-state Marx generator [80]. Therefore, there is still significant room for improvement with our solid-state IMG system, which will have to come from shorter pulses and faster-rise time pulses. 
Table 1. Overview of characteristic electrical quantities as function of rise time and pulse shape at $9 \mathrm{kV}$ peak voltage in air and nitrogen: $V_{\text {inc }} \ldots$ applied voltage at streamer inception, $E_{\text {inc }} \ldots$ electric field strength at inception (calculated assuming a symmetric wire-to-cylinder geometry with $V_{\text {inc }}$ applied to the wire), $E_{\text {tot }} \ldots$ electrical energy consumed (complete discharge), $Q_{\text {tot }} \ldots$ transferred electrical charge (determined by integration of discharge current of the complete discharge); the given errors are the standard deviation obtained from 100 single measurements for each quantity.

\begin{tabular}{|c|c|c|c|c|c|c|c|c|}
\hline \multirow[t]{2}{*}{ Quantity (unit) } & \multirow[t]{2}{*}{ Gas } & \multicolumn{3}{|c|}{ Regular pulse rise time $t_{10 \%-90 \%}$} & \multicolumn{4}{|c|}{ Step-shaped pulse } \\
\hline & & $6.8 \mathrm{~ns}$ & $19.5 \mathrm{~ns}$ & $26.2 \mathrm{~ns}$ & $2 \mathrm{~S} .40 \mathrm{D}$ & $3 \mathrm{~S} .40 \mathrm{D}$ & $4 \mathrm{~S} .40 \mathrm{D}$ & 5S.40D \\
\hline \multirow{2}{*}{$V_{\text {inc }}[\mathrm{kV}]$} & Air & $6.6 \pm 0.5$ & $5.9 \pm 0.5$ & $5.0 \pm 0.5$ & $5.40 \pm 0.75$ & $5.20 \pm 0.25$ & $6.2 \pm 0.6$ & $7.5 \pm 1.0$ \\
\hline & Nitrogen & $5.60 \pm 0.25$ & $5.10 \pm 0.25$ & $4.7 \pm 0.2$ & $6.1 \pm 0.2$ & $5.60 \pm 0.15$ & $6.9 \pm 0.2$ & $6.30 \pm 0.35$ \\
\hline \multirow{2}{*}{$E_{\mathrm{inc}}\left[\mathrm{kV} \mathrm{mm}^{-1}\right]$} & Air & $26 \pm 2$ & $23 \pm 2$ & $20 \pm 2$ & $21 \pm 3$ & $20 \pm 1$ & $24.0 \pm 2.4$ & $30 \pm 4$ \\
\hline & Nitrogen & $22 \pm 1$ & $20 \pm 1$ & $19 \pm 1$ & $24.0 \pm 0.8$ & $22.0 \pm 0.6$ & $27.0 \pm 0.8$ & $25.0 \pm 1.4$ \\
\hline \multirow{2}{*}{$E_{\text {tot }}[\mathrm{mJ}]$} & Air & $1.97 \pm 0.03$ & $2.08 \pm 0.03$ & $2.57 \pm 0.10$ & $1.00 \pm 0.02$ & $0.62 \pm 0.01$ & $1.78 \pm 0.08$ & $1.88 \pm 0.08$ \\
\hline & Nitrogen & $0.56 \pm 0.02$ & $0.54 \pm 0.02$ & $0.75 \pm 0.04$ & $0.35 \pm 0.01$ & $0.37 \pm 0.01$ & $0.38 \pm 0.02$ & $0.50 \pm 0.04$ \\
\hline \multirow{2}{*}{$Q_{\text {tot }}[\mathrm{nC}]$} & Air & $277 \pm 7$ & $296 \pm 7$ & $341 \pm 12$ & $141 \pm 6$ & $88 \pm 8$ & $284 \pm 18$ & $294 \pm 12$ \\
\hline & Nitrogen & $94 \pm 3$ & $87 \pm 6$ & $118 \pm 8$ & $58 \pm 6$ & $65 \pm 7$ & $66 \pm 7$ & $88 \pm 12$ \\
\hline
\end{tabular}

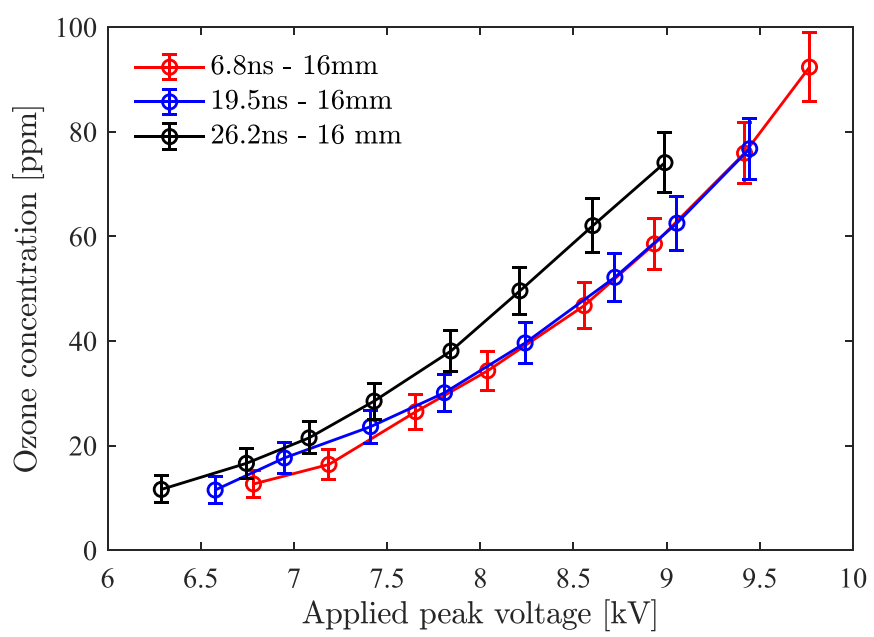

(a)

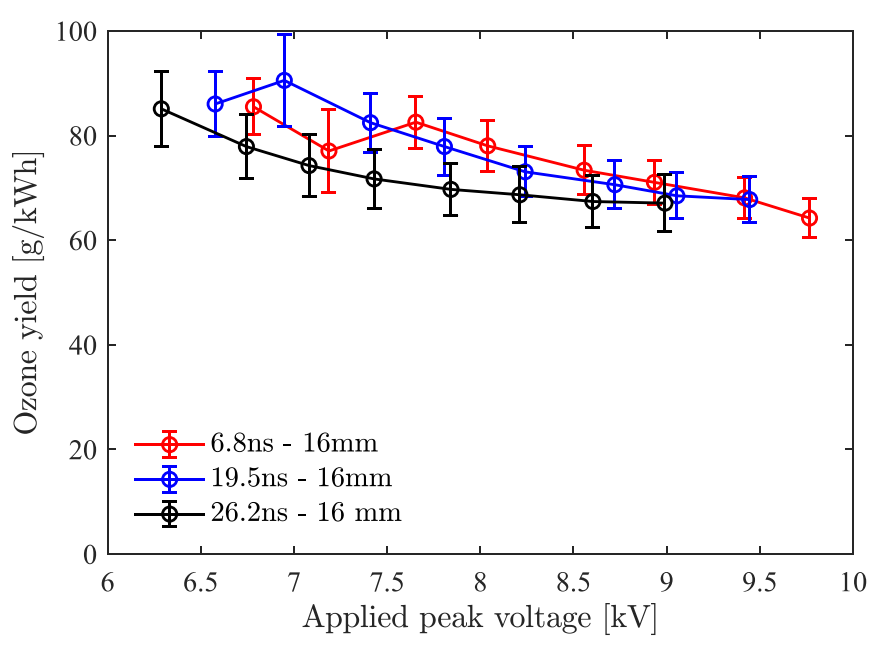

(b)

Figure 21. Ozone yield measurements as a function of rise time and voltage. For these experiments, we used a $21 \mathrm{~min}^{-1}$ flow of synthetic air and ran the pulse source at a repetition rate of $100 \mathrm{~Hz}$ and a pulse duration of $80 \mathrm{~ns}$.

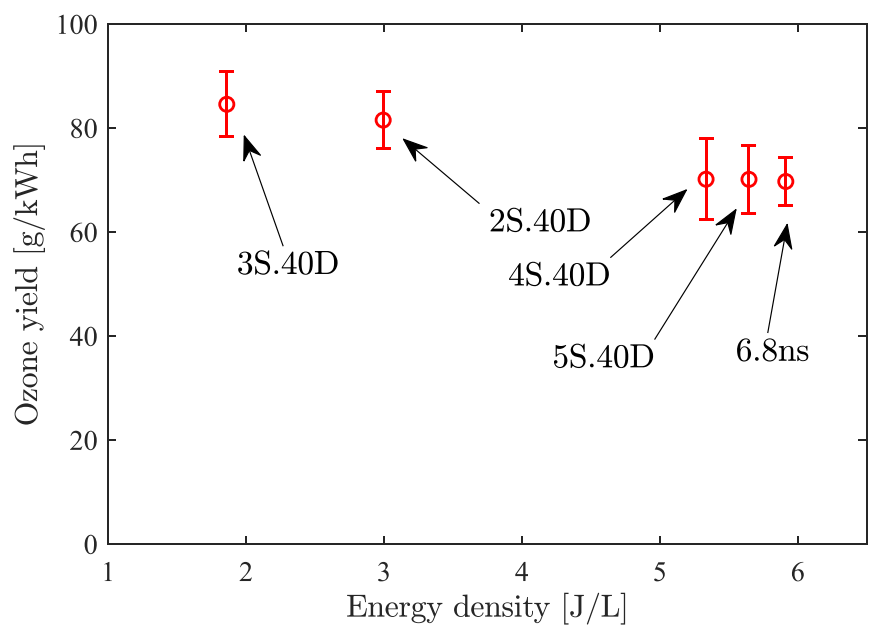

Figure 22. Ozone yield measurements as a function of the rising edge shape and energy density. For these experiments, we used a $21 \mathrm{~min}^{-1}$ flow of synthetic air and ran the pulse source at a repetition rate of $100 \mathrm{~Hz}$ and a peak voltage of $9 \mathrm{kV}$.

The pulses we used in e.g. [14] (1-9 ns pulse duration, up to $45 \mathrm{kV}$ amplitude), [34] (12 ns pulse duration, up to 20 $\mathrm{kV}$ amplitude) and [81] (7 ns pulse duration, up to $45 \mathrm{kV}$ amplitude) all resulted in yields of over $150 \mathrm{~g} \mathrm{kWh}^{-1}$. What these pulses all had in common is that in the plasma reactor systems we applied them to, they all significantly exceeded the inception voltage (so the gap was over-volted). Therefore, the streamers propagated very fast (almost ten times faster than in the present study) and then the short pulse durations ensured that the streamers existed only in the primary streamer phase. By developing the solid-state IMG for shorter and higher-voltage pulses, we also aim to operate in such regimes, but unlike in the other studies we will then be able to do this completely with an arbitrary-waveform, solid-state pulse source. 


\section{Conclusions and outlook}

In this paper we presented our solid-state nanosecond pulse source (the solid-state IMG) which can generate arbitrary waveforms and which can be used for pulsed discharge generation. In the presented study, we applied the arbitrary-waveform pulse source to streamer discharge generation in a $16 \mathrm{~mm}$ cylinder-wire-like arrangement and used the arbitrary-waveform capability to change the rise time of $80 \mathrm{~ns}$ duration, $6-10 \mathrm{kV}$ positive pulses and to introduce variations of a step in the rising edge of the waveform. We performed these measurements both in air and nitrogen and measured ozone generation (in air) and analyzed the streamer propagation in the plasma reactor with ICCD imaging.

When changing the rise time of the pulses from 6.8 to $26.2 \mathrm{~ns}$ we saw overall differences between air and nitrogen (faster, less bright and less branched streamers in air), but not as a function of rise time. Using a slower-rising pulse only delayed the streamer inception, but hardly influenced the propagation afterwards and additionally showed no significant effect on ozone production. When a step in the waveform was introduced the results showed that only if the initial step was large enough did we see an effect on the streamer propagation: the streamers start during the first step, then stop and finally reignite or start over and cross the gap during the full application of the voltage. Concluding: while we can indeed control the streamer discharge with the stepped waveform we need to study this effect further once the solid-state IMG can work over a wider range of pulse settings (higher voltages, lower pulse durations, etc).

Additionally, the ozone measurements showed no great difference between the waveforms. We measured a higher ozone yield for certain stepped waveforms, but that was likely more an effect of a lower energy density associated with those waveforms. A full discussion on the effect of streamer phases on the ozone yields will be left for future work.

Finally, the results presented in this paper are of course only a glimpse of what will be possible with arbitrary waveform high-voltage pulse generation. While the current implementations of the solid-state IMG in our lab are great for testing principles and first experimentation, they still lack in certain areas for fast transient plasma generation: the shortest rise time is currently around $6 \mathrm{~ns}$ (depending on the load), the shortest pulse duration is around $60 \mathrm{~ns}$ and the time resolution with which we can control the stages is around $5 \mathrm{~ns}$. However, we are working on a new generation that can produce pulses of up to $30 \mathrm{kV}$ with pulse durations of down to $20 \mathrm{~ns}$, a rise time of around $3 \mathrm{~ns}$ and a time resolution to control the stages of $100 \mathrm{ps}$. Additionally, we are working on versions of over $100 \mathrm{kV}$.

\section{Data availability statement}

The data that support the findings of this study are available upon reasonable request from the authors.

\section{Acknowledgments}

This work was supported by the Dutch Research Organisation NWO under Grant No. 16830 and partly by the DFG Project MultiFil (Project No. 408777255).

\section{ORCID iDs}

T Huiskamp (1) https://orcid.org/0000-0002-8450-2600

H Höft (1) https://orcid.org/0000-0002-9224-4103

\section{References}

[1] Kim H H 2004 Plasma Process. Polym. 1 91-110

[2] Nijdam S, Teunissen J and Ebert U 2020 Plasma Sources Sci. Technol. 29103001

[3] Kogelschatz U 2003 Plasma Chem. Plasma Process. 23 1-46

[4] Samukawa S et al 2012 J. Phys. D: Appl. Phys. 45253001

[5] Adamovich I et al 2017 J. Phys. D: Appl. Phys. 50323001

[6] Murugesan P et al 2020 J. Environ. Chem. Eng. 8104377

[7] Beckers F J C M, Hoeben W F L M, Huiskamp T, Pemen A J M and van Heesch E J M 2013 IEEE Trans. Plasma Sci. 41 2920-5

[8] Barjasteh A, Dehghani Z, Lamichhane P, Kaushik N, Choi E H and Kaushik N K 2021 Appl. Sci. 113372

[9] Wang D and Namihira T 2020 Plasma Sources Sci. Technol. 29023001

[10] Puač N, Gherardi M and Shiratani M 2018 Plasma Process. Polym. 151700174

[11] Bruggeman P J et al 2016 Plasma Sources Sci. Technol. 25053002

[12] Pemen A J M, Van Ooij P P, Beckers F J C M, Hoeben W F L M, Koonen-Reemst A M C B, Huiskamp T and Leenders P H M 2017 IEEE Trans. Plasma Sci. 45 2725-33

[13] Hoeben W F L M, Van Ooij P P, Schram D C, Huiskamp T, Pemen A J M and Lukeš P 2019 Plasma Chem. Plasma Process. 39 597-626

[14] Huiskamp T, Hoeben W F L M, Beckers F J C M, van Heesch E J M and Pemen A J M 2017 J. Phys. D: Appl. Phys. 50405201

[15] van Heesch E J M, Winands G J J and Pemen A J M 2008 J. Phys. D: Appl. Phys. 41234015

[16] Matsumoto T, Wang D, Namihira T and Akiyama H 2010 IEEE Trans. Plasma Sci. 38 2639-43

[17] Wang D, Namihira T and Akiyama H 2011 J. Adv. Oxid. Technol. 14 131-7

[18] Matsumoto T, Wang D, Namihira T and Akiyama H 2011 Jpn. J. Appl. Phys. $\mathbf{5 0}$ 08JF14

[19] Fujiwara M 2006 Jpn. J. Appl. Phys. 45948

[20] Kakuta T, Yagi I and Takaki K 2015 Jpn. J. Appl. Phys. 54 01AG02

[21] Ono R, Nakagawa Y and Oda T 2011 J. Phys. D: Appl. Phys. 44485201

[22] Namihira T, Tsukamoto S, Wang D, Katsuki S, Hackam R, Akiyama H, Uchida Y and Koike M 2000 IEEE Trans. Plasma Sci. 28 434-42

[23] Komuro A, Ryu T, Yoshino A, Namihira T, Wang D and Ono R 2021 J. Phys. D: Appl. Phys. 54364004

[24] Yagi I, Okada S, Matsumoto T, Wang D, Namihira T and Takaki K 2011 IEEE Trans. Plasma Sci. 39 2232-3

[25] Clevis T T J, Nijdam S and Ebert U 2012 J. Phys. D: Appl. Phys. 46045202

[26] Park D P, Davis K, Gilani S, Alonzo C A, Dobrynin D, Friedman G, Fridman A, Rabinovich A and Fridman G 2013 Curr. Appl. Phys. 13 S19-S29 
[27] Kornev I, Osokin G, Galanov A, Yavorovskiy N and Preis S 2013 Ozone Sci. Eng. 35 22-30

[28] Baek E J, Joh H M, Kim S J and Chung T H 2016 Phys. Plasmas 23073515

[29] Takahashi K, Satoh K, Itoh H, Kawaguchi H, Timoshkin I, Given M and MacGregor S 2016 Jpn. J. Appl. Phys. 55 07LF01

[30] Lu P, Boehm D, Bourke P and Cullen P J 2017 Plasma Process. Polym. 141600207

[31] Höft H, Becker M M, Loffhagen D and Kettlitz M 2016 Plasma Sources Sci. Technol. 25064002

[32] Huiskamp T 2020 Plasma Sources Sci. Technol. 29023002

[33] Rukin S N 1999 Instrum. Exp. Tech. 42 439-67

[34] Huiskamp T, Subramanian S, Gururajan V, Schroeder W P, Schroeder C A, Gundersen M A and Cronin S B 2020 IEEE Trans. Plasma Sci. 48 245-57

[35] Redondo L M, Canacsinh H and Silva J F 2009 IEEE Trans. Dielectr. Electr. Insul. 16 1037-42

[36] Jiang W, Sugiyama H and Tokuchi A 2014 IEEE Trans. Plasma Sci. 42 3603-8

[37] Holma J and Barnes M J 2014 IEEE Trans. Plasma Sci. 42 2899-908

[38] Huiskamp T and Van Oorschot J J 2019 IEEE Trans. Plasma Sci. 47 4350-60

[39] Teunissen J and Ebert U 2016 Plasma Sources Sci. Technol. 25044005

[40] Teunissen J and Ebert U 2017 J. Phys. D: Appl. Phys. 50474001

[41] Li X, Dijcks S, Nijdam S, Sun A, Ebert U, Teunissen J 2021 Comparing simulations and experiments of positive streamers in air: steps toward model validation Plasma Sources Sci. Technol. 30095002

[42] Höft H, Becker M M, Kolb J F and Huiskamp T 2020 Plasma Sources Sci. Technol. 29085002

[43] Marx E 1924 Elektr. Z. 45 652-4

[44] Koval'chuk B M et al 1997 Russ. Phys. J. 40 1142-53

[45] Stygar W A et al 2017 Phys. Rev. Accel. Beams 20040402

[46] Kazemi M R, Sugai T, Tokuchi A and Jiang W 2017 IEEE Trans. Plasma Sci. 45 247-51

[47] Kazemi M R, Sugai T, Tokuchi A and Jiang W 2017 IEEE Trans. Plasma Sci. 45 2323-7

[48] Huiskamp T, Beckers F J C M, van Heesch E J M and Pemen A J M 2016 IEEE Sens. J. 16 3792-801

[49] Novac B M, Xiao R, Huiskamp T, Pécastaing L, Wang M, Senior P, De Ferron A S, Pemen A and Rivaletto M 2018 IEEE Trans. Plasma Sci. 46 2985-92

[50] Beckers F J C M 2015 Pulsed power driven industrial plasma processing PhD Thesis Eindhoven University of Technology (available at: https://research.tue.nl/files/ 10243336/20151215_Beckers.pdf)

[51] Huiskamp T, Sengers W, Beckers F J C M, Nijdam S, Ebert U, van Heesch E J M and Pemen A J M 2017 Plasma Sources Sci. Technol. 26075009

[52] Huiskamp T, Sengers W and Pemen A J M 2016 Rev. Sci. Instrum. 87123509

[53] Huiskamp T, Beckers F J C M, Hoeben W F L M, van Heesch E J M and Pemen A J M 2016 Plasma Sources Sci. Technol. 25054006
[54] Kozlov K V, Brandenburg R, Wagner H E, Morozov A M and Michel P 2005 J. Phys. D: Appl. Phys. 38 518-29

[55] Pancheshnyi S V, Starikovskaia S M and Starikovskii A Y 2000 Chem. Phys. 262 349-57

[56] Ono R and Oda T 2003 J. Phys. D: Appl. Phys. 361952

[57] Nijdam S, Van De Wetering F M J H, Blanc R, Van Veldhuizen E M and Ebert U 2010 J. Phys. D: Appl. Phys. 43145204

[58] Li Y, Dijcks S, Sun G, Wen J, Xu Y, Zhang G, Ebert U and Nijdam U 2020 Plasma Sources Sci. Technol. 2903 LT02

[59] Pancheshnyi S 2005 Plasma Sources Sci. Technol. 14 645-53

[60] Sigmond R S 1984 J. Appl. Phys. 56 1355-70

[61] Winands G J J, Liu Z, Pemen A J M, Van Heesch E J M and Yan K 2008 J. Phys. D: Appl. Phys. 41234001

[62] Briels T M P, Van Veldhuizen E M and Ebert U 2008 J. Phys. D: Appl. Phys. 41234008

[63] Namihira T, Wang D, Katsuki S, Hackam R and Akiyama H 2003 IEEE Trans. Plasma Sci. 31 1091-4

[64] Tardiveau P, Marode E and Agneray A 2002 J. Phys. D: Appl. Phys. 352823

[65] Won J Y and Williams P F 2002 J. Phys. D: Appl. Phys. 35205

[66] Wang D, Jikuya M, Yoshida S, Namihira T, Katsuki S and Akiyama H 2007 IEEE Trans. Plasma Sci. 35 1098-103

[67] Komuro A, Ono R and Oda T 2013 Plasma Sources Sci. Technol. 22045002

[68] Yoshinaga K, Okada S, Wang D, Namihira T, Katsuki S and Akiyama H 2009 Acta Phys. Pol. A 1151050

[69] Vasilyak L M, Vetchinin S P and Polyakov D N 1999 Tech. Phys. Lett. 25 749-51

[70] Babaeva N Y and Naidis G V 2016 Phys. Plasmas 23083527

[71] Eichwald O, Ducasse O, Dubois D, Abahazem A, Merbahi N, Benhenni M and Yousfi M 2008 J. Phys. D: Appl. Phys. 41234002

[72] Ono R and Oda T 2004 J. Phys. D: Appl. Phys. 37730

[73] Komuro A, Takahashi K and Ando A 2015 J. Phys. D: Appl. Phys. 48215203

[74] Wang D, Matsumoto T, Namihira T and Akiyama H $2010 \mathrm{~J}$. Adv. Oxid. Technol. 13 71-78

[75] Kitayama J and Kuzumoto M 1999 J. Phys. D: Appl. Phys. 323032

[76] Braun D, Kuchler U and Pietsch G 1988 Pure Appl. Chem. $60741-6$

[77] Simek M and Clupek M 2002 J. Phys. D: Appl. Phys. 351171

[78] Shimomura N, Wakimoto M, Togo H, Namihira T and Akiyama $\mathrm{H} 2003$ Production of ozone using nanosecond short pulsed power Digest of Technical Papers. PPC-2003. 14th IEEE Int. Pulsed Conf. vol 2 (IEEE) pp 1290-3

[79] Eliasson B and Kogelschatz U 1991 IEEE Trans. Plasma Sci. 19 309-23

[80] Huiskamp T, Oorschot J J, Pereira M T and Redondo L M 2018 Ozone generation with a flexible solid-state Marx generator 2018 IEEE Int. Power Modulator and High Conf. (IPMHVC) (IEEE)

[81] Huiskamp T, Takamura N, Namihira T and Pemen A J M 2015 IEEE Trans. Plasma Sci. 43 617-24 